\title{
Immunoelectron Microscopic Characterization of Vasopressin-Producing Neurons in the Hypothalamo-Pituitary Axis of Non-Human Primates by Use of Formaldehyde-Fixed Tissues Stored at $-25{ }^{\circ} \mathrm{C}$ for Several Years
}

\author{
Akito Otubo ${ }^{1}$, Sho Maejima ${ }^{1}$, Takumi Oti ${ }^{1,2}{ }^{\mathbb{D}}$, Keita Satoh ${ }^{1,3} \mathbb{D}$, Yasumasa Ueda ${ }^{4,5}$, John F. Morris ${ }^{6}$, \\ Tatsuya Sakamoto ${ }^{1}$ and Hirotaka Sakamoto ${ }^{1,6, * \mathbb{D}}$
}

1 Ushimado Marine Institute (UMI), Graduate School of Natural Science and Technology, Okayama University, Ushimado, Setouchi, Okayama 701-4303, Japan; pasw3k6m@s.okayama-u.ac.jp (A.O.); maejima@okayama-u.ac.jp (S.M.); oti-bio@kanagawa-u.ac.jp (T.O.); k.satoh@med.kawasaki-m.ac.jp (K.S.); ryu@uml.okayama-u.ac.jp (T.S.)

2 Department of Biological Sciences, Faculty of Science, Kanagawa University, Hiratsuka, Kanagawa 259-1293, Japan

check for

updates

Citation: Otubo, A.; Maejima, S.; Oti,

T.; Satoh, K.; Ueda, Y.; Morris, J.F.;

Sakamoto, T.; Sakamoto, H.

Immunoelectron Microscopic

Characterization of

Vasopressin-Producing Neurons in the Hypothalamo-Pituitary Axis of Non-Human Primates by Use of

Formaldehyde-Fixed Tissues Stored

at $-25{ }^{\circ} \mathrm{C}$ for Several Years. Int. J.

Mol. Sci. 2021, 22, 9180. https://

doi.org/10.3390/ijms22179180

Academic Editors:

Kazunori Kageyama and

Takahiro Nemoto

Received: 5 August 2021

Accepted: 21 August 2021

Published: 25 August 2021

Publisher's Note: MDPI stays neutra with regard to jurisdictional claims in published maps and institutional affiliations.

Copyright: (c) 2021 by the authors Licensee MDPI, Basel, Switzerland. This article is an open access article distributed under the terms and conditions of the Creative Commons Attribution (CC BY) license (https:// creativecommons.org/licenses/by/ $4.0 /)$
3 Department of Anatomy, Kawasaki Medical School, Kurashiki, Okayama 701-0192, Japan

4 Department of Physiology, Kyoto Prefectural University of Medicine, Kyoto 602-8566, Japan; uedaya@hirakata.kmu.ac.jp

5 Department of Physiology, Kansai Medical University, Shinmachi, Hirakata, Osaka 573-1191, Japan

6 Department of Physiology, Anatomy \& Genetics, University of Oxford, South Parks Road, Oxford OX1 3QX, UK; john.morris@dpag.ox.ac.uk

* Correspondence: hsakamo@okayama-u.ac.jp; Tel.: +81-869-34-5210

\begin{abstract}
Translational research often requires the testing of experimental therapies in primates, but research in non-human primates is now stringently controlled by law around the world. Tissues fixed in formaldehyde without glutaraldehyde have been thought to be inappropriate for use in electron microscopic analysis, particularly those of the brain. Here we report the immunoelectron microscopic characterization of arginine vasopressin (AVP)-producing neurons in macaque hypothalamopituitary axis tissues fixed by perfusion with $4 \%$ formaldehyde and stored at $-25^{\circ} \mathrm{C}$ for several years (4-6 years). The size difference of dense-cored vesicles between magnocellular and parvocellular AVP neurons was detectable in their cell bodies and perivascular nerve endings located, respectively, in the posterior pituitary and median eminence. Furthermore, glutamate and the vesicular glutamate transporter 2 could be colocalized with AVP in perivascular nerve endings of both the posterior pituitary and the external layer of the median eminence, suggesting that both magnocellular and parvocellular AVP neurons are glutamatergic in primates. Both ultrastructure and immunoreactivity can therefore be sufficiently preserved in macaque brain tissues stored long-term, initially for light microscopy. Taken together, these results suggest that this methodology could be applied to the human post-mortem brain and be very useful in translational research.
\end{abstract}

Keywords: vasopressin; corticotrophin-releasing factor; glutamate; paraventricular nucleus of the hypothalamus; Japanese macaque monkey; post-embedding immunoelectron microscopy; densecored neurosecretory vesicle

\section{Introduction}

Studies using macaque monkeys as model non-human primates are essential because of their high applicability to human clinical research which often requires the testing of experimental therapies in primates. However, primate research is now stringently controlled by law around the world [1]. Rodents, in which research is less restricted, are often not sufficiently analogous to humans in their physiology to allow an extrapolation from rodent to human. Medical science is urged to make minimal use of animals such as 
primates, and basic studies on non-human primates appear to be permitted only if the work could not be carried out in any other species. Thus, although tissues from primates are often essential to achieve relevant results, there are considerable problems in their use.

Arginine vasopressin (AVP), an anti-diuretic hormone, is released, not only into the blood stream, but also into the central nervous system where, in mammals, it has been shown to be important for stress coping, aggression, courtship behavior, learning, bonding, and various socio-sexual behaviors [2]. AVP is produced mainly by magnocellular neurosecretory neurons in the supraoptic nucleus $(\mathrm{SON})$ and paraventricular nucleus (PVN) of the hypothalamus [3]. The AVP gene encodes a precursor containing AVP, AVPassociated neurophysin II (NPII), and a glycopeptide copeptin [4-6]. The expression and release of AVP by magnocellular neurosecretory neurons in the SON and PVN are regulated by physiological conditions, including plasma osmotic pressure and blood pressure [7]. The magnocellular axons project primarily via the internal layer of the median eminence to the posterior pituitary where they release AVP into the systemic circulation. In addition, some parvocellular neurons in the PVN produce AVP and project into extrahypothalamic areas where the AVP and/or other co-packaged molecules regulate brain function as neuromodulators [8].

Corticotrophin-releasing factor (CRF) is a strong stimulator of adrenocorticotrophic hormone $(\mathrm{ACTH})$ secretion from the anterior pituitary when released onto portal capillaries in the median eminence in response to the stress [9]. A population of parvocellular neurons in the anteromedial part of the PVN produces CRF and may, depending on the extent of stress, also produce AVP. Both peptides released into the hypothalamo-hypophysial portal circulation play an important synergistic role in stress resilience [10-13]. Because intense AVP- and CRF-immunoreactivity have both been observed in the external layer of the macaque median eminence, the peptides are probably co-released into the portal circulation to amplify ACTH release from the primate anterior pituitary [14,15].

In rodents, the presence of glutamate-immunoreactivity in magnocellular neuroendocrine cells of the SON suggests that AVP neurons also produce glutamate as a neurotransmitter $[16,17]$. Within the neurosecretory endings of the posterior pituitary, glutamate immunoreactivity is specifically localized to electron-lucent microvesicles with no overlap onto the dense-cored neurosecretory vesicle (dcv) population in rats [16]. Immunocytochemical co-localization of CRF and the vesicular glutamate transporter 2 (VGLUT2) in the locus coeruleus of rats suggests that the co-release of CRF and glutamate may function to regulate postsynaptic targets [18]. It is currently unclear whether glutamate has a similar or other functions in the primate hypothalamo-pituitary paraventricular AVP/CRF system.

Tissues, especially those of the brain, fixed in formaldehyde without glutaraldehyde have long been thought to be unsuitable for electron microscopic analysis by reason of the weaker cross-linking action of formaldehyde, e.g., $[19,20]$. Here we report the immunoelectron microscopic characterization of AVP-producing neurons in the primate hypothalamo-pituitary axis tissue fixed by perfusion with formaldehyde and stored at $-25^{\circ} \mathrm{C}$ for several years. Special attention was paid to the size of dev in AVP-producing magno- and parvocellular neurons and to the colocalization of CRF with AVP-related gene products in the dcv. We show that immunoelectron microscopy of formaldehyde-fixed tissue can confirm the well-known size difference in dcv between magno- and parvocellular AVP neurons in Japanese macaque monkeys. Furthermore, we show that, in formaldehydefixed stored neural tissue of macaque monkeys, both AVP/CRF and VGLUT2/glutamate can be co-localized in both the magnocellular endings of the posterior pituitary and the parvocellular endings in the external layer of the median eminence.

\section{Results}

2.1. Antibody Characterization and the Expression of VGLUT2 at the Protein Level in the Posterior Pituitary

Full details of all the antibodies used in this study are shown in Table 1. We first validated by Western blot analysis the specificity for the VGLUT2 and NPII antibodies in Japanese macaque monkeys. Western blot analysis demonstrated the specificity for the 
guinea pig polyclonal antibody against VGLUT2 and the expression of VGLUT2 at the protein level in the posterior pituitary; a single strong immunoreactive band was detected at the expected molecular weight of $\sim 56 \mathrm{kDa}$ [21] (Figure 1). The mouse monoclonal antibody against AVP-neurophysin II (NPII) also detected a single major band at the expected molecular weight of $\sim 12 \mathrm{kDa}$ on the blots of posterior pituitary [14,22] (Figure 1).

Table 1. Primary antibodies used in this study.

\begin{tabular}{|c|c|c|c|c|c|}
\hline Antigen & Description & $\begin{array}{l}\text { Source, Host Species, } \\
\text { Cat \#, or Code \# }\end{array}$ & Working Dilution & Reference \# & RRID \\
\hline Copeptin & $\begin{array}{c}\text { Synthetic peptide } \\
\text { mapping at the amino } \\
\text { acids } 7-14 \text { of } \\
\text { human/mouse copeptin }\end{array}$ & $\begin{array}{l}\text { Generated by our } \\
\text { laboratory, rabbit } \\
\text { polyclonal, CP8 }\end{array}$ & $\begin{array}{l}1: 10,000(\mathrm{IF}) \\
1: 100(\mathrm{EM})\end{array}$ & {$[14,22,23]$} & AB_2722604 \\
\hline CRF & $\begin{array}{l}\text { Human/rat CRF coupled } \\
\text { to human alpha-globulins } \\
\text { via bis-diazotized } \\
\text { benzidine }\end{array}$ & $\begin{array}{c}\text { Donated by Dr. W. Vale, } \\
\text { rabbit polyclonal, PBL } \\
\text { rC70 }\end{array}$ & $\begin{array}{l}1: 20,000(\mathrm{IF}) \\
1: 5000(\mathrm{EM})\end{array}$ & {$[14,24,25]$} & AB_2314234 \\
\hline NPII & $\begin{array}{l}\text { Soluble proteins extracted } \\
\text { from the posterior } \\
\text { pituitary of the rat }\end{array}$ & $\begin{array}{l}\text { ATCC, mouse monoclonal, } \\
\text { PS41, CRL-1799 }\end{array}$ & $\begin{array}{c}1: 1000(\mathrm{IF}) \\
1: 200(\mathrm{EM}) \\
1: 1000(\mathrm{WB})\end{array}$ & {$[14,26-28]$} & AB_2313960 \\
\hline VGLUT2 & $\begin{array}{l}\text { Recombinant protein } \\
\text { corresponding to amino } \\
\text { acids } 510-582 \text { of } \\
\text { the rat VGLUT2 }\end{array}$ & $\begin{array}{l}\text { Synaptic Systems, guinea } \\
\text { pig polyclonal, } 135404\end{array}$ & $\begin{array}{c}1: 20(\mathrm{EM}) \\
1: 10,000(\mathrm{WB})\end{array}$ & {$[29,30]$} & AB_887884 \\
\hline L-Glutamate & $\begin{array}{l}\text { L-Glutamate conjugated to } \\
\text { glutaraldehyde }\end{array}$ & $\begin{array}{c}\text { Abcam, rabbit } \\
\text { polyclonal, ab9440 }\end{array}$ & 1:10 (EM) & {$[31,32]$} & AB_307256 \\
\hline
\end{tabular}

Abbreviations: ATCC, American Type Culture Collection; CRF, corticotropin-releasing factor; EM, immunoelectron microscopy; IF, immunofluorescence; NPII, arginine vasopressin-associated neurophysin II; RRID, research resource identifier; VGLUT2, vesicular glutamate transporter 2; WB, Western blotting; \#, number.

\subsection{Anatomy of AVP-Producing Neurons in the Macaque Hypothalamus}

Immunostaining for NPII was performed to study the localization of AVP neurons in the hypothalamus of Japanese macaque monkeys. Numerous magnocellular (large-sized) AVP neurons were observed in the PVN (Figure 2A) and SON (Figure 2B). Parvocellular (small-sized) AVP neurons were also observed in the PVN (Figure 2C). The median eminence can be divided into an internal and an external layer. The internal layer is the zone through which the axons of magnocellular neurons densely project into the posterior pituitary (Figure 2D) $[3,8,15]$. The external layer of the median eminence is where the axons of many parvocellular neurosecretory neurons, including parvocellular AVP/CRF neurons of the PVN, end on hypothalamo-hypophysial portal vessels and release anterior pituitary-hormone-regulating hormones (Figure 2D) [3,8,15]. 


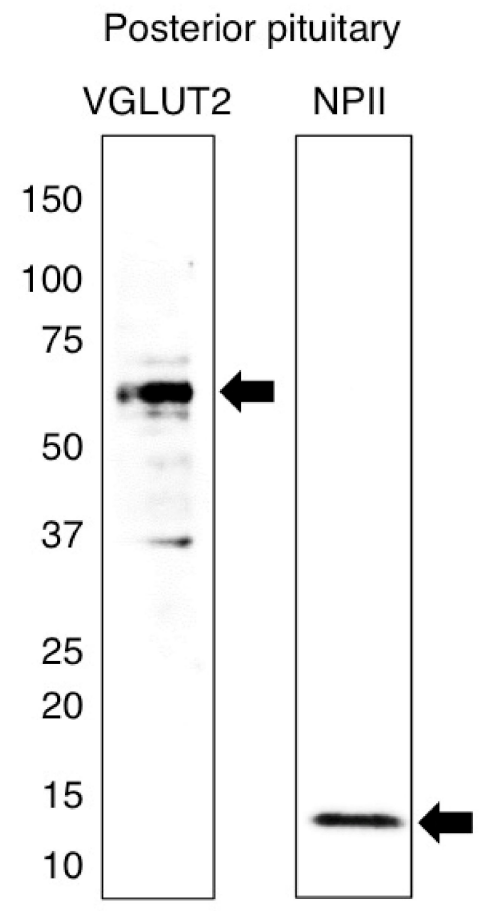

Figure 1. Western immunoblotting of vesicular glutamate transporter 2 (VGLUT2) and vasopressinassociated neurophysin (NPII). The number on the left indicates the molecular weight (kDa). Extracts of protein from the posterior pituitary of the Japanese macaque monkey were transferred onto polyvinylidene difluoride membranes and probed with the guinea pig polyclonal antiserum against VGLUT2 or with the mouse monoclonal antibody against NPII. The antisera recognized a single major band at the expected molecular weight of VGLUT2 $(\sim 56 \mathrm{kDa})$ or NPII ( 12 kDa) on a Western blot of the macaque posterior pituitary.
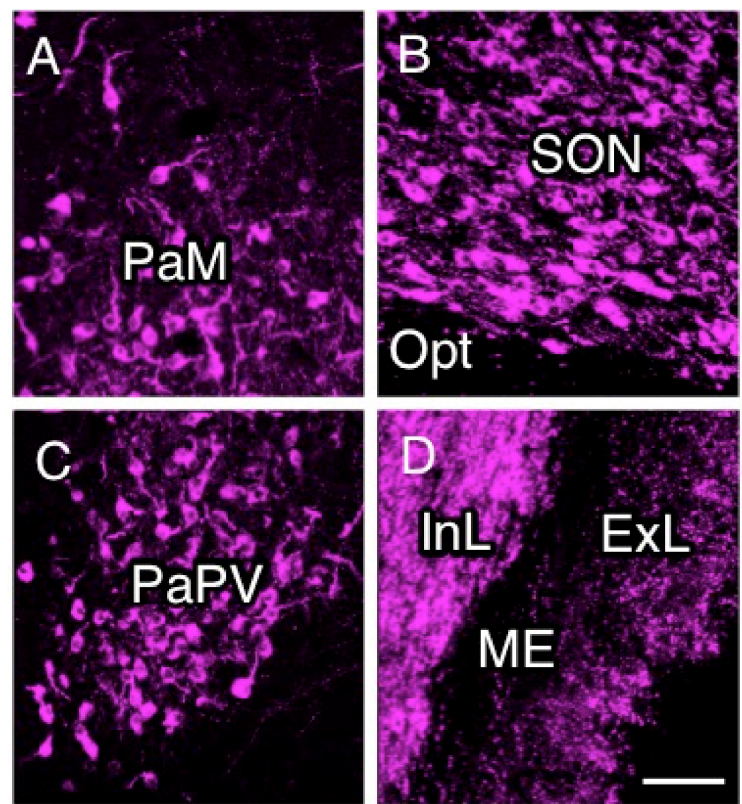

Figure 2. Immunofluorescence for vasopressin-associated neurophysin (NPII) in the macaque hypothalamus. NPII-immunoreactivity was observed in the paraventricular nucleus (PVN) of the hypothalamus; PaM, magnocellular part of the PVN (A); supraoptic nucleus (B); PaPV, parvocellular part of the PVN, ventral division (C); and median eminence (ME) (D). Opt, optic nerve; InL, internal layer of the ME; ExL, external layer of the ME. Scale bar, $100 \mu \mathrm{m}$. 
In this study, immunoelectron microscopic characterization of AVP-producing neurons was performed in macaque hypothalamo-pituitary axis tissues fixed with $4 \%$ formaldehyde and stored at $-25{ }^{\circ} \mathrm{C}$ for several years. We found that both ultrastructure and immunoreactivity are sufficiently preserved in macaque brain tissues stored long-term, initially for light microscopy. Immunoelectron microscopy of the posterior pituitary showed many AVP dcv containing both NPII (PS41)- and copeptin (CP8)-immunoreactivity (Figure 3A,B). In other neighboring endings, no NPII- or copeptin-immunoreactivity was detectable (Figure 3C). In the median eminence, many dcv showing PS41/CP8 double-immunoreactivity were observed in both the internal and external layers (Figure 4). However, the AVP dcv in the internal layer (magnocellular) of the median eminence (Figure 4B) were larger than those in the external layer (parvocellular) of the median eminence (Figure 4D).

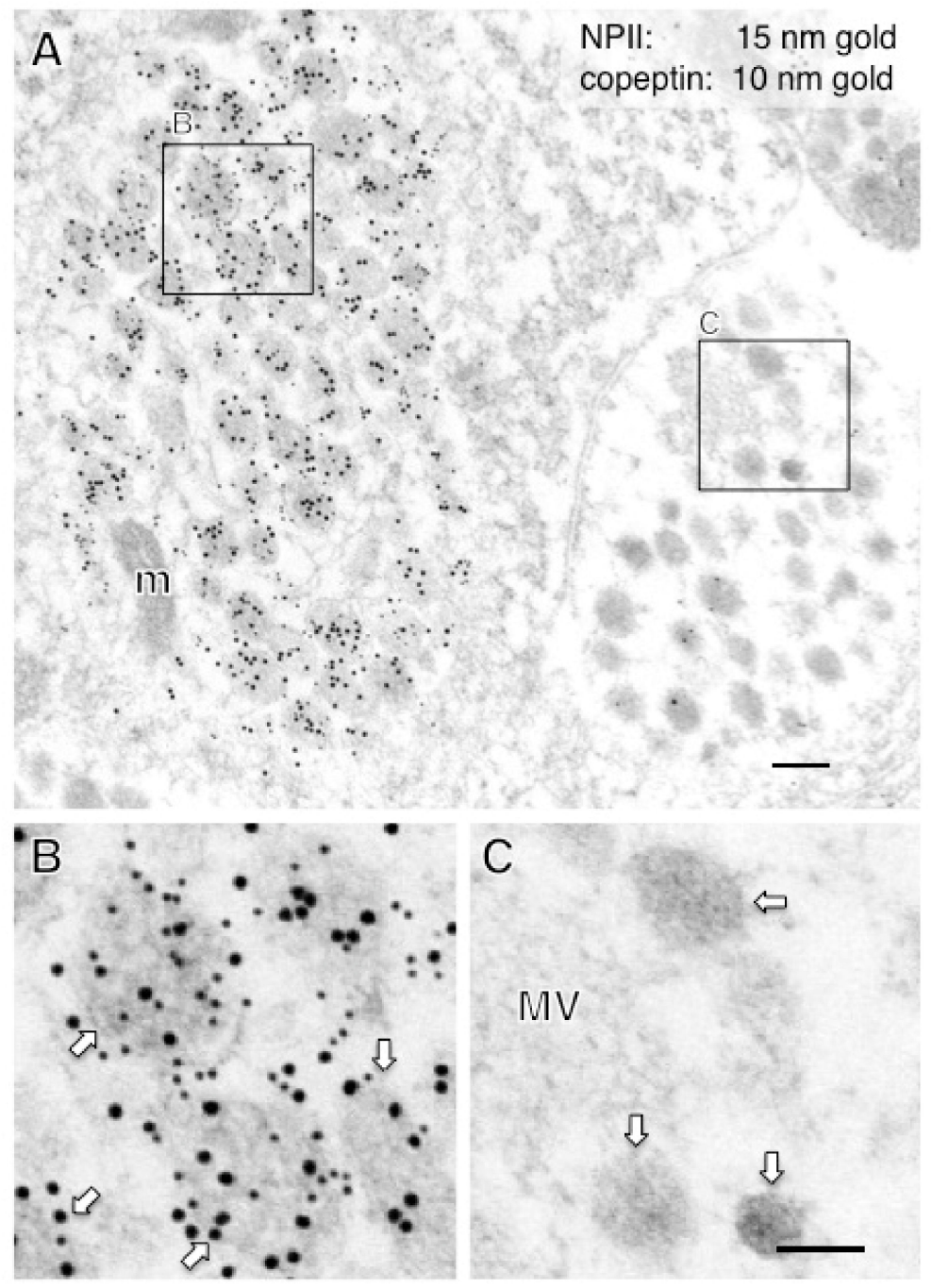

Figure 3. Double-label immunoelectron microscopy for vasopressin-associated neurophysin (NPII) and copeptin in the macaque posterior pituitary. Numerous neurosecretory vesicles located in some of the varicosities were doubly immunopositive for copeptin (10-nm gold particles) and NPII (15-nm gold particles). The outlined areas in (A) are enlarged in (B,C). In contrast, in other presumably oxytocin-containing varicosities, no NPII/copeptin-immunoreactivity was detected (A,C). Scale bars, $200 \mathrm{~nm}$, and $100 \mathrm{~nm}$ in enlarged images. Arrows indicate dense-cored neurosecretory vesicles. $\mathrm{m}$, mitochondrion; $\mathrm{MV}$, clustered microvesicles. 

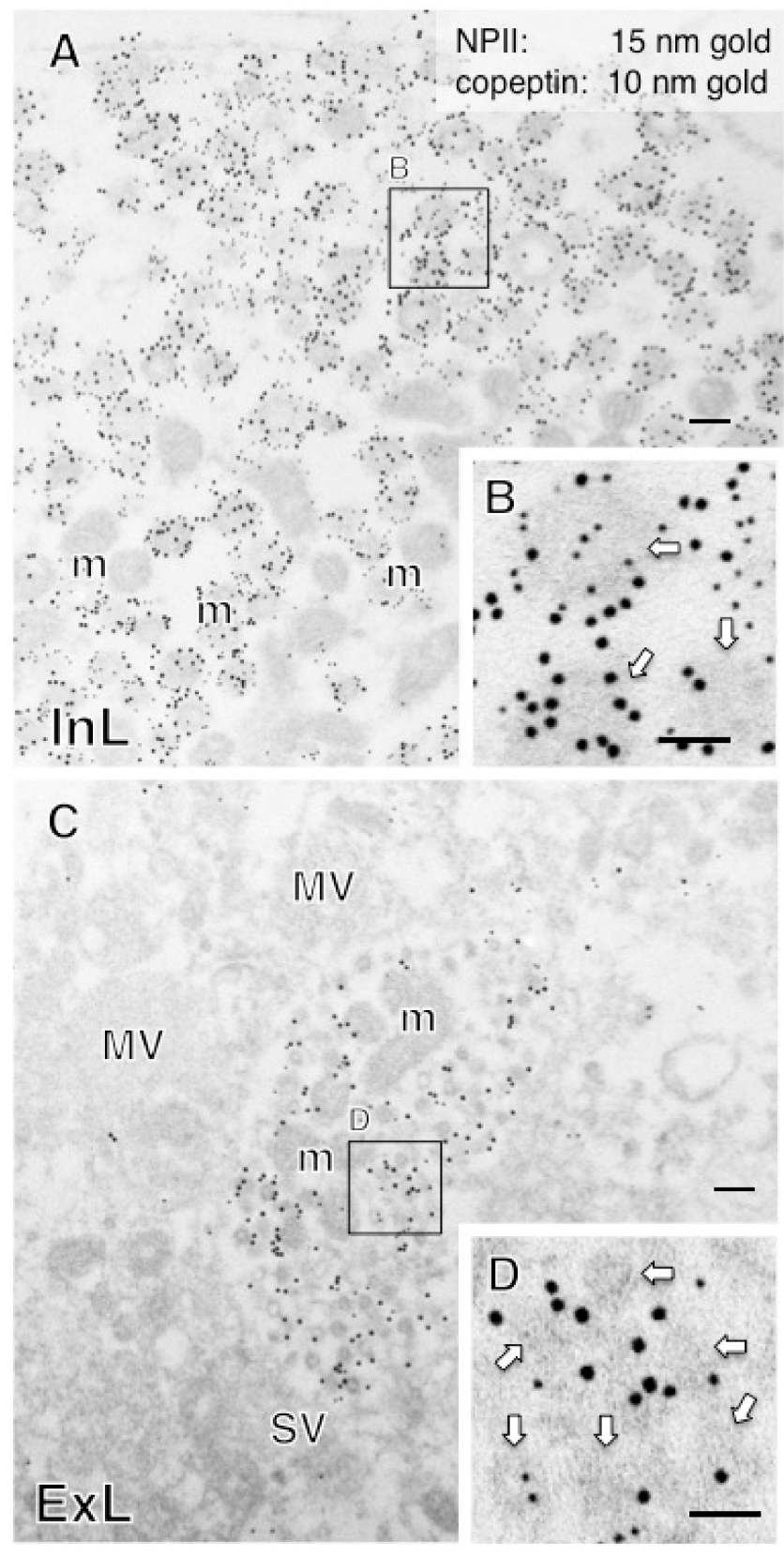

Figure 4. Double-label immunoelectron microscopy for vasopressin-associated neurophysin (NPII) and copeptin in the internal layer $(\operatorname{InL} ;(\mathbf{A}, \mathbf{B}))$ and external layer $(\operatorname{ExL} ;(\mathbf{C}, \mathbf{D}))$ of the macaque median eminence. Numerous dense-cored neurosecretory vesicles located in some of the varicosities were immunopositive for both copeptin (10-nm gold particles) and NPII (15-nm gold particles). The outlined area in (A) and (C) is enlarged in (B) and (D), respectively. Scale bars, $200 \mathrm{~nm}$, and $100 \mathrm{~nm}$ in enlarged images. Arrows indicate dense-cored neurosecretory vesicles. $\mathrm{m}$, mitochondrion; MV, clustered microvesicles.

\subsection{Size Characterization of Dcv}

Approximately $200 \mathrm{dcv}$ in the neurosecretory axons in the posterior pituitary (magnocellular), the internal layer of the median eminence (magnocellular), and the external layer of the median eminence (parvocellular) were selected and their major axis diameters were measured. The average of major axis was $196 \pm 2 \mathrm{~nm}$ in the posterior pituitary, $197 \pm 2 \mathrm{~nm}$ in the internal layer of the median eminence, but significantly smaller $(93 \pm 1 \mathrm{~nm})$ in the external layer of the median eminence (Figure 5; Table 2). 


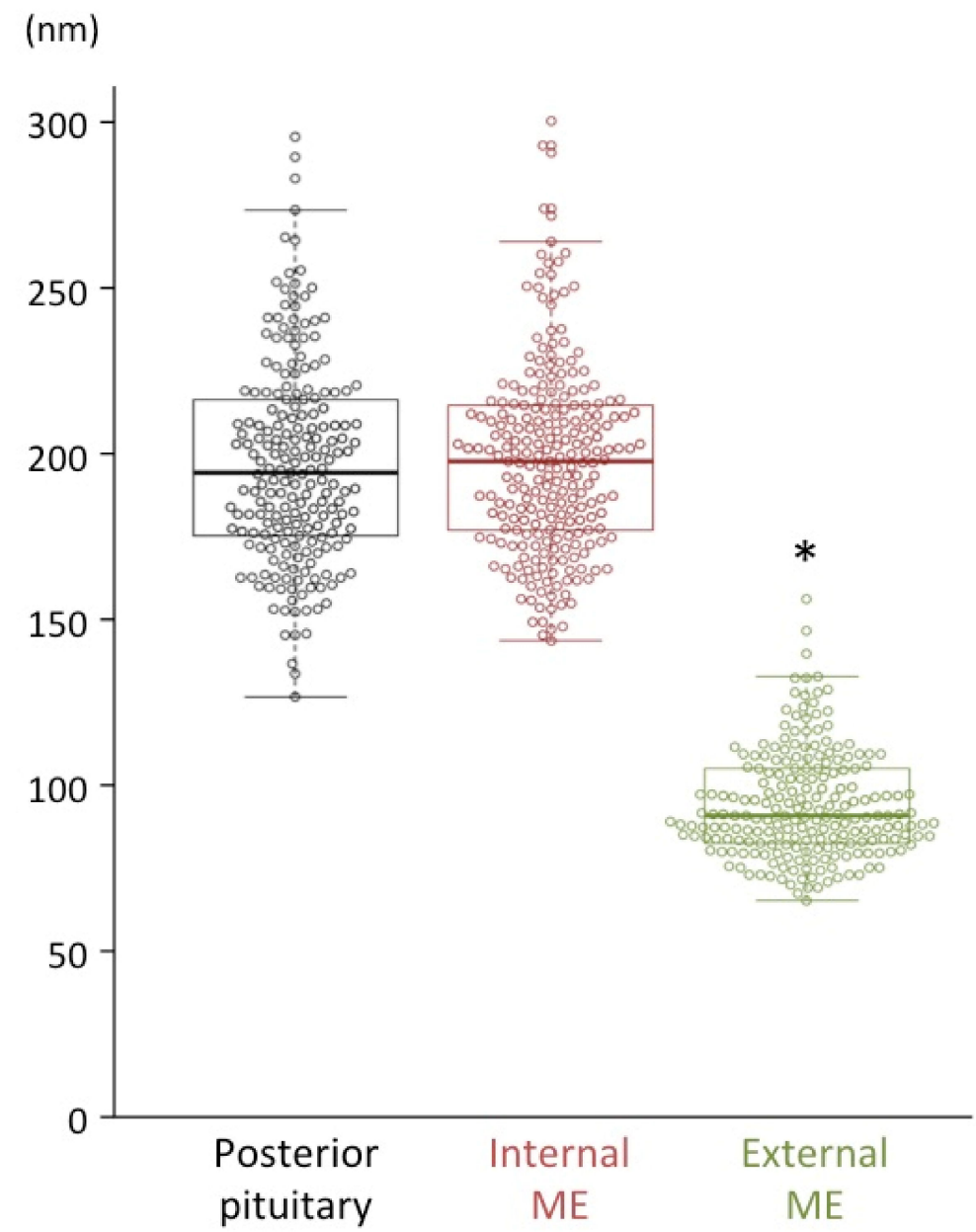

Figure 5. Bee-swarm and box plots displaying the major axis of dense-cored neurosecretory vesicles distributed in the posterior pituitary (black), internal layer of the median eminence (ME) (red), and external layer of the ME (green) in macaque monkeys. The major axis of dense-cored vesicles in the posterior pituitary and the internal layer of the ME $(\sim 200 \mathrm{~nm})$ was significantly larger than that of the vesicles in the external layer of the $\mathrm{ME}(\sim 100 \mathrm{~nm}) .{ }^{*} p<0.05$, vs. posterior pituitary and internal layer of the ME.

Table 2. Identification of cell types (magno- or parvocellular neurons) based on the major axis of dense-cored neurosecretory vesicles.

\begin{tabular}{ccccc}
\hline Region & Major Axis $(\mathbf{n m})$ & Magno or Parvo & Number of Vesicles Examined & Identification \\
\hline Posterior pituitary & $196 \pm 2$ & Magno & 205 & AVP \\
Internal ME & $197 \pm 2$ & Magno & 237 & AVP without CRF \\
External ME & $93 \pm 1^{*}$ & Parvo & 212 & CRF \\
\hline
\end{tabular}

$\mathrm{AVP}$, arginine vasopressin; internal ME, internal layer of the median eminence; $\mathrm{CRF}$, corticotrophin-releasing factor; external ME, external layer of the median eminence. ${ }^{*} p<0.05$, vs. posterior pituitary and internal layer of the median eminence. All data values are presented as mean \pm standard error of the mean (SEM).

Next, we measured the diameter of dcv in the perikarya of randomly selected SON and PVN AVP neurosecretory neurons (at $\times 5000$ magnification; Table 3 ). In the SON ( 7 cell bodies), the average diameter of $\mathrm{dcv}$ contained in the cell body was $204 \pm 12 \mathrm{~nm}$ (11 vesicles), confirming that, as expected, all AVP neurons in the SON are magnocellular (Figure 6; Table 3). The 18 AVP neurons in the PVN selected for analysis formed two distinct groups: those with larger dcv $(180 \pm 19 \mathrm{~nm}$; 11 vesicles in Figure 7A,B) identified as magnocellular; and those with smaller $\mathrm{dcv}(102 \pm 10 \mathrm{~nm}$; 14 vesicles in Figure 7C,D) identified as parvocellular neurons. 


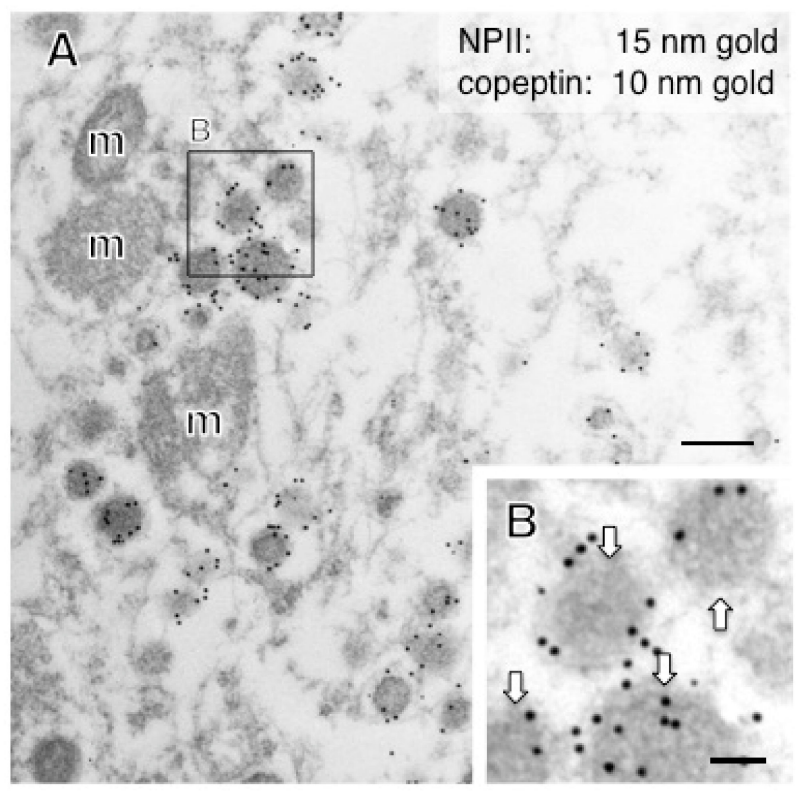

Figure 6. Double-label immunoelectron microscopy for vasopressin-associated neurophysin (NPII) and copeptin in the macaque supraoptic nucleus (SON). Many dense-cored neurosecretory vesicles located in the cell body were doubly immunopositive for copeptin (10-nm gold particles) and NPII (15-nm gold particles). The outlined area in (A) is enlarged in (B). Scale bars, $200 \mathrm{~nm}$, and $100 \mathrm{~nm}$ in the enlarged image. Arrows indicate dense-cored neurosecretory vesicles. $\mathrm{m}$, mitochondrion.

Table 3. Characterization of cell types (magno- or parvocellular neurons) based on the major axis of dense-cored neurosecretory vesicles.

\begin{tabular}{|c|c|c|c|c|c|}
\hline Cell Body & $\begin{array}{l}\text { Major Axis } \\
\quad(\mathrm{nm})\end{array}$ & $\begin{array}{c}\text { Magno or } \\
\text { Parvo }\end{array}$ & $\begin{array}{c}\text { Number of } \\
\text { Vesicles } \\
\text { Examined }\end{array}$ & SON or PVN & Identification \\
\hline$\# 1$ & $187 \pm 5 *$ & Magno & 29 & SON & AVP \\
\hline$\# 2$ & $175 \pm 6^{*}$ & Magno & 35 & SON & AVP \\
\hline$\# 3$ & $189 \pm 10^{*}$ & Magno & 24 & SON & AVP \\
\hline$\# 4$ & $181 \pm 5^{*}$ & Magno & 26 & SON & AVP \\
\hline \#5 & $171 \pm 7 *$ & Magno & 25 & SON & AVP \\
\hline$\# 6$ & $195 \pm 6^{*}$ & Magno & 30 & SON & AVP \\
\hline \#7 & $205 \pm 6^{*}$ & Magno & 46 & SON & AVP \\
\hline$\# 8$ & $188 \pm 5^{*}$ & Magno & 49 & PVN & AVP \\
\hline$\# 9$ & $170 \pm 5$ * & Magno & 20 & PVN & AVP \\
\hline$\# 10$ & $169 \pm 8^{*}$ & Magno & 22 & PVN & AVP \\
\hline$\# 11$ & $172 \pm 4^{*}$ & Magno & 24 & PVN & AVP \\
\hline$\# 12$ & $184 \pm 5$ * & Magno & 25 & PVN & AVP \\
\hline$\# 13$ & $182 \pm 5 *$ & Magno & 21 & PVN & AVP \\
\hline$\# 14$ & $103 \pm 5+$ & Parvo & 38 & PVN & AVP \\
\hline$\# 15$ & $98 \pm 4+$ & Parvo & 42 & PVN & CRF \\
\hline$\# 16$ & $109 \pm 4+$ & Parvo & 51 & PVN & CRF \\
\hline$\# 17$ & $93 \pm 5+$ & Parvo & 24 & PVN & CRF \\
\hline$\# 18$ & $107 \pm 5+$ & Parvo & 40 & PVN & CRF \\
\hline$\# 19$ & $103 \pm 4+$ & Parvo & 35 & PVN & CRF \\
\hline$\# 20$ & $110 \pm 7+$ & Parvo & 42 & PVN & CRF \\
\hline \#21 & $108 \pm 5+$ & Parvo & 77 & PVN & CRF \\
\hline$\# 22$ & $93 \pm 4+$ & Parvo & 81 & PVN & CRF \\
\hline$\# 23$ & $95 \pm 5+$ & Parvo & 30 & PVN & CRF \\
\hline$\# 24$ & $120 \pm 6^{*},+$ & (Parvo) & 40 & PVN & CRF \\
\hline \#25 & $113 \pm 3^{*},+$ & (Parvo) & 89 & PVN & CRF \\
\hline
\end{tabular}

AVP, arginine vasopressin; CRF, corticotrophin-releasing factor; SON, supraoptic nucleus; PVN, paraventricular nucleus; \#, number. ${ }^{*} p<0.05$, vs. external layer of the median eminence; $+p<0.05$, vs. posterior pituitary and internal layer of the median eminence. All data values are presented as mean \pm standard error of the mean (SEM). 

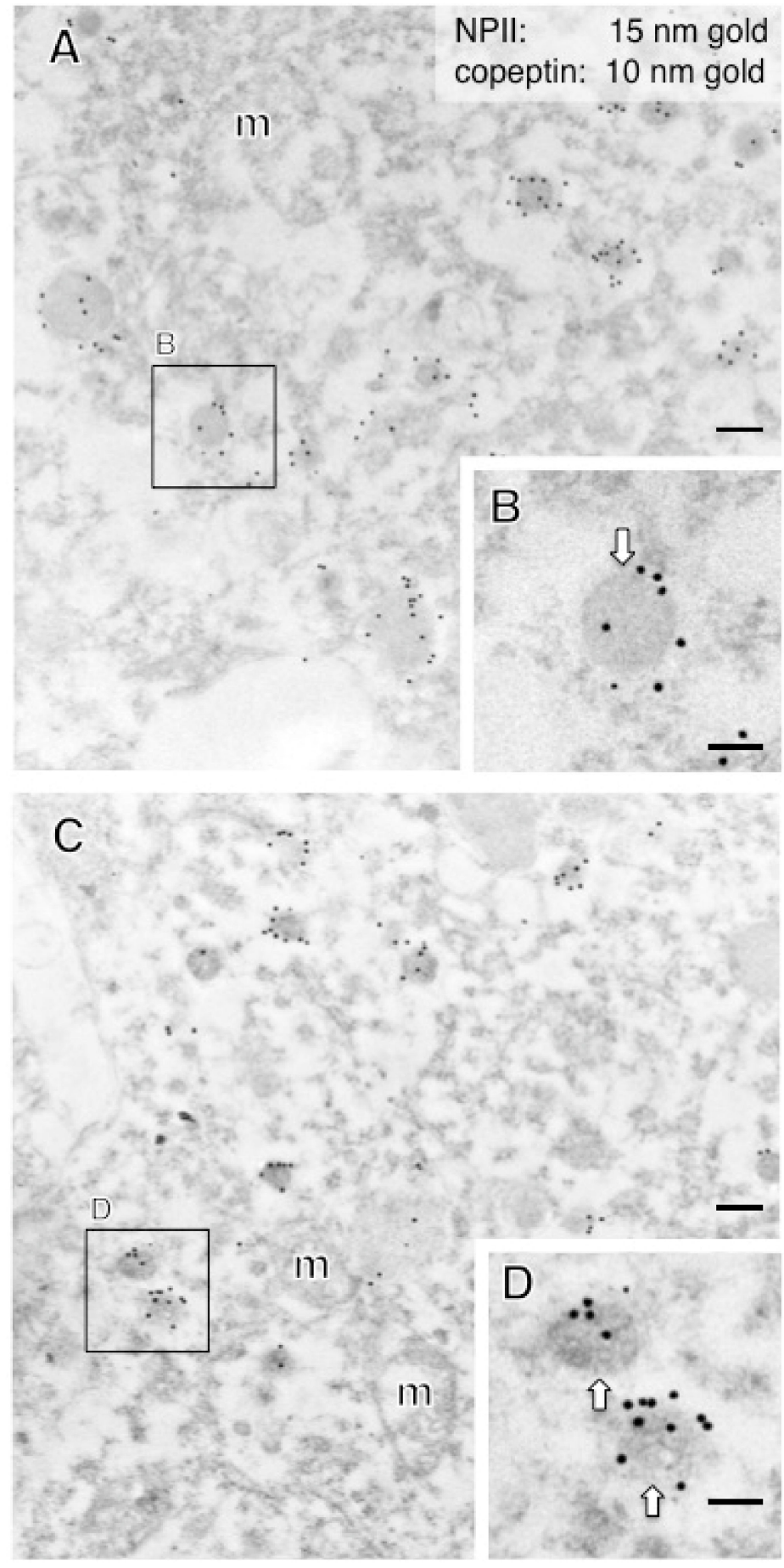

Figure 7. Double-label immunoelectron microscopy for vasopressin-associated neurophysin (NPII) and copeptin in the macaque paraventricular nucleus (PVN) of the hypothalamus. (A) In the cell body of a putative magnocellular vasopressin neuron, many dense-cored neurosecretory vesicles located in the cell body were doubly immunopositive for copeptin (10-nm gold particles) and NPII (15-nm gold particles). (C) Similar results are obtained in the cell body of a putative parvocellular vasopressin neuron. The size of dense-cored vesicles in $(\mathbf{A}, \mathbf{B})$ was larger than that of vesicles in $(\mathbf{C}, \mathbf{D})$. The outlined areas are enlarged. Scale bars, $200 \mathrm{~nm}$, and $100 \mathrm{~nm}$ in enlarged images. Arrows indicate dense-cored neurosecretory vesicles. $\mathrm{m}$, mitochondrion. 


\subsection{A Subpopulation of Parvocellular AVP Neurons in the PVN Co-Expresses CRF}

In the PVN, of the $18 \mathrm{AVP}$ neuronal cell bodies analyzed, 6 were identified as magnocellular on the basis of vesicle size; none of these showed any CRF-immunoreactivity. Of the $12 \mathrm{PVN}$ perikarya identified as parvocellular on the basis of vesicle size, a subpopulation (especially in the parvocellular part of the PVN) co-expressed CRF (Figure 8) and such neurons were more intermingled with magnocellular neurons in the macaque monkey than in rodent PVN as reported previously [14,25,33]. The terminal regions of parvocellular AVP/CRF neurons in the external layer of the median eminence were next analyzed (Figure 9). In these cells, the major axis diameter of the sparse dcv was $106 \pm 3 \mathrm{~nm}$ (16 vesicles) (Figure 10) for the vesicles in the CRF-immunoreactive terminals, comparable to the $113 \pm 9 \mathrm{~nm}$ (12 vesicles) in the cell body (Figure 11). In two putative parvocellular neurons ( $\# 24$ and \#25), the mean major axis of the dcv appeared slightly larger which might relate to the maturity of the vesicles (Table 3) [34].
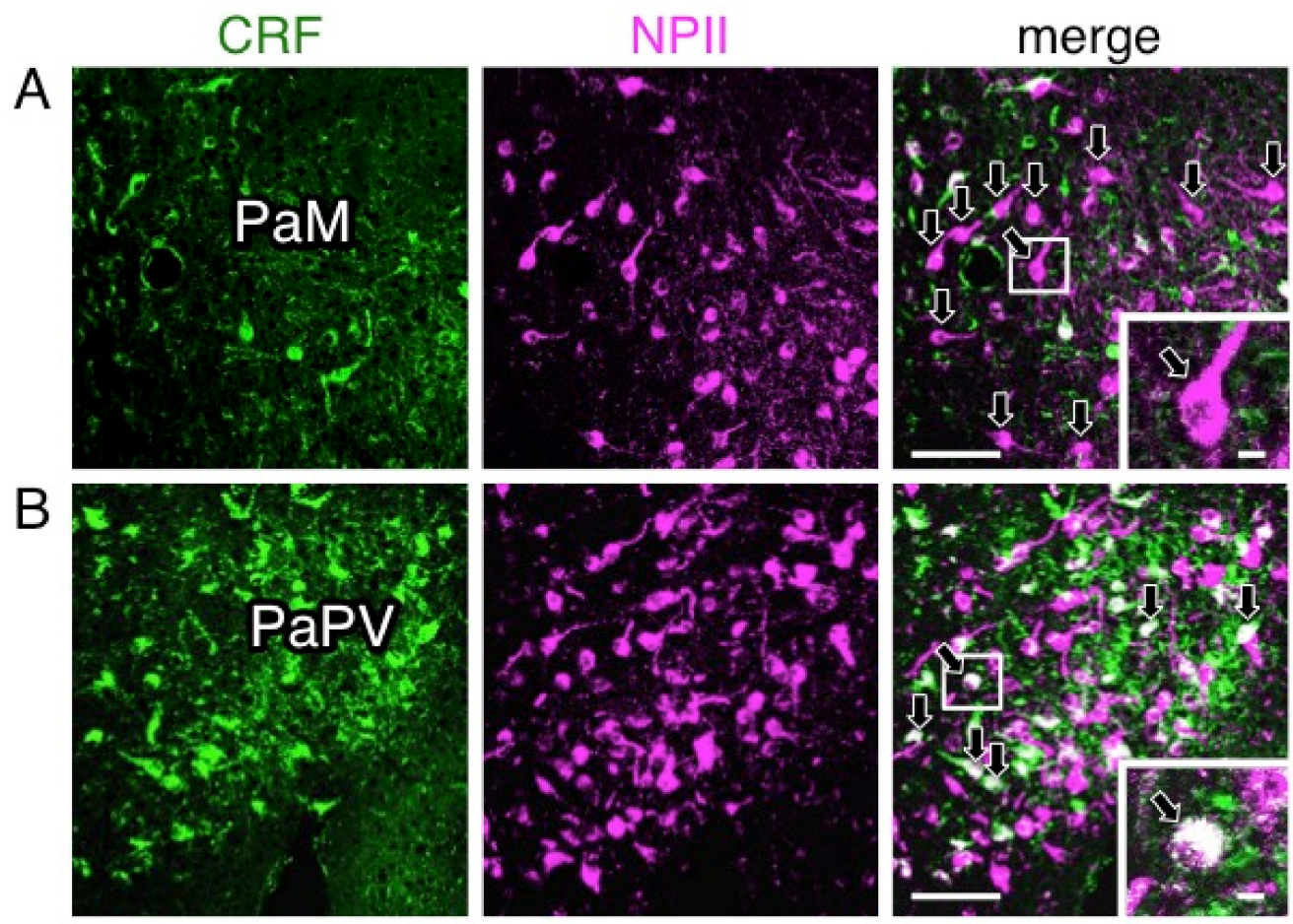

Figure 8. Double-label immunofluorescence for corticotrophin-releasing factor (CRF) and vasopressinassociated neurophysin (NPII) in the paraventricular nucleus (PVN) of the macaque hypothalamus; PaM, magnocellular part of the PVN (A); PaPV, parvocellular part of the PVN, ventral division (B). Immunoreactivity against CRF (green) and NPII (magenta) is merged in each right-hand panel (overlap; white). The outlined areas in merged images are enlarged. Arrows in (A; merged) indicate perikarya single-immunopositive for NPII in the PaM. Arrows in (B; merged) indicate doubly immunopositive for CRF and NPII in the PaPV. Scale bars, $100 \mu \mathrm{m}$, and $10 \mu \mathrm{m}$ in enlarged images. 

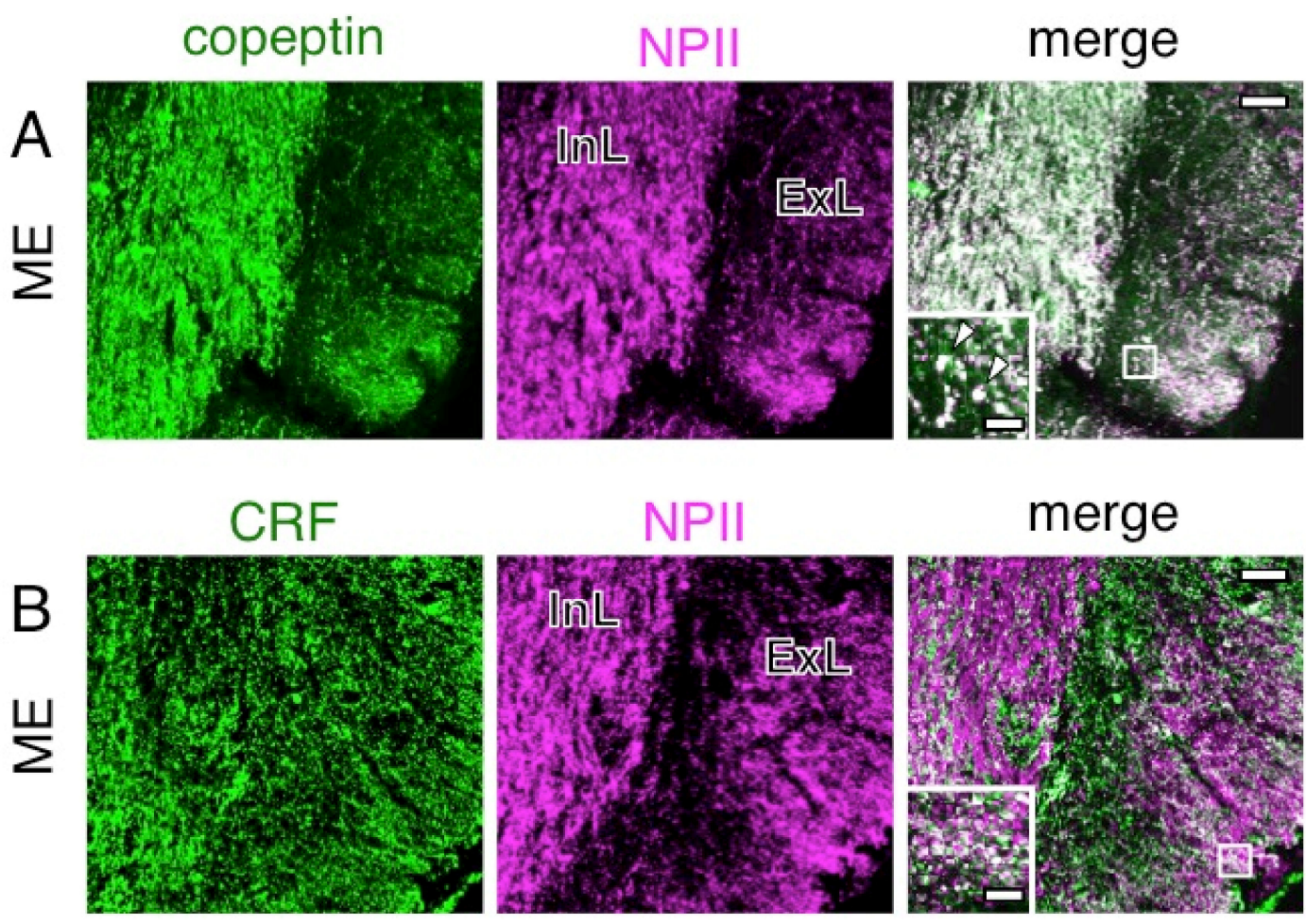

Figure 9. Double-label immunofluorescence for copeptin (A) or corticotrophin-releasing factor (CRF) (B) and vasopressinassociated neurophysin (NPII) in the macaque median eminence (ME). Immunoreactivity against copeptin (A; green) or CRF (B; green) and NPII (magenta) is merged in each right-hand panel (overlap; white). The outlined areas in merged images are enlarged. Arrowheads in (A) indicate tissue doubly immunopositive for copeptin and NPII. Scale bars, $50 \mu \mathrm{m}$, and $10 \mu \mathrm{m}$ in enlarged images. InL, internal layer of the ME; ExL, external layer of the ME.

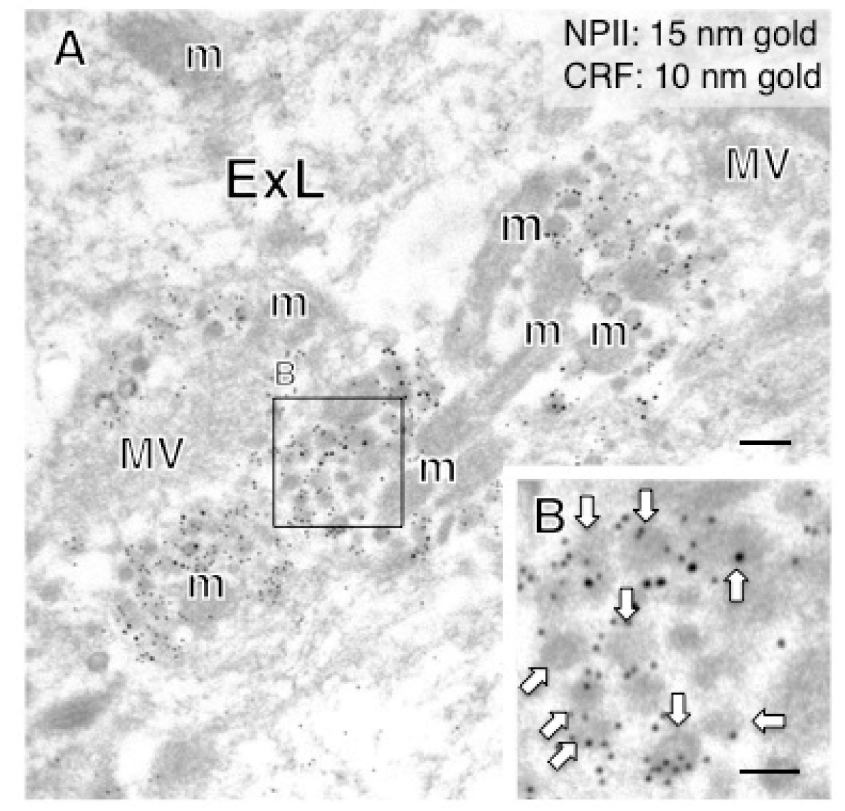

Figure 10. Double-label immunoelectron microscopy for vasopressin-associated neurophysin (NPII) and corticotrophin-releasing factor (CRF) in the external layer (ExL) of the macaque median eminence. In some axonal varicosities, numerous dense-cored neurosecretory vesicles were doubly immunopositive for CRF (10-nm gold particles) and NPII (15-nm gold particles). The outlined area in (A) is enlarged in (B). Scale bars, $200 \mathrm{~nm}$, and $100 \mathrm{~nm}$ in the enlarged image. Arrows indicate dense-cored neurosecretory vesicles. $\mathrm{m}$, mitochondrion; MV, clustered microvesicles. 


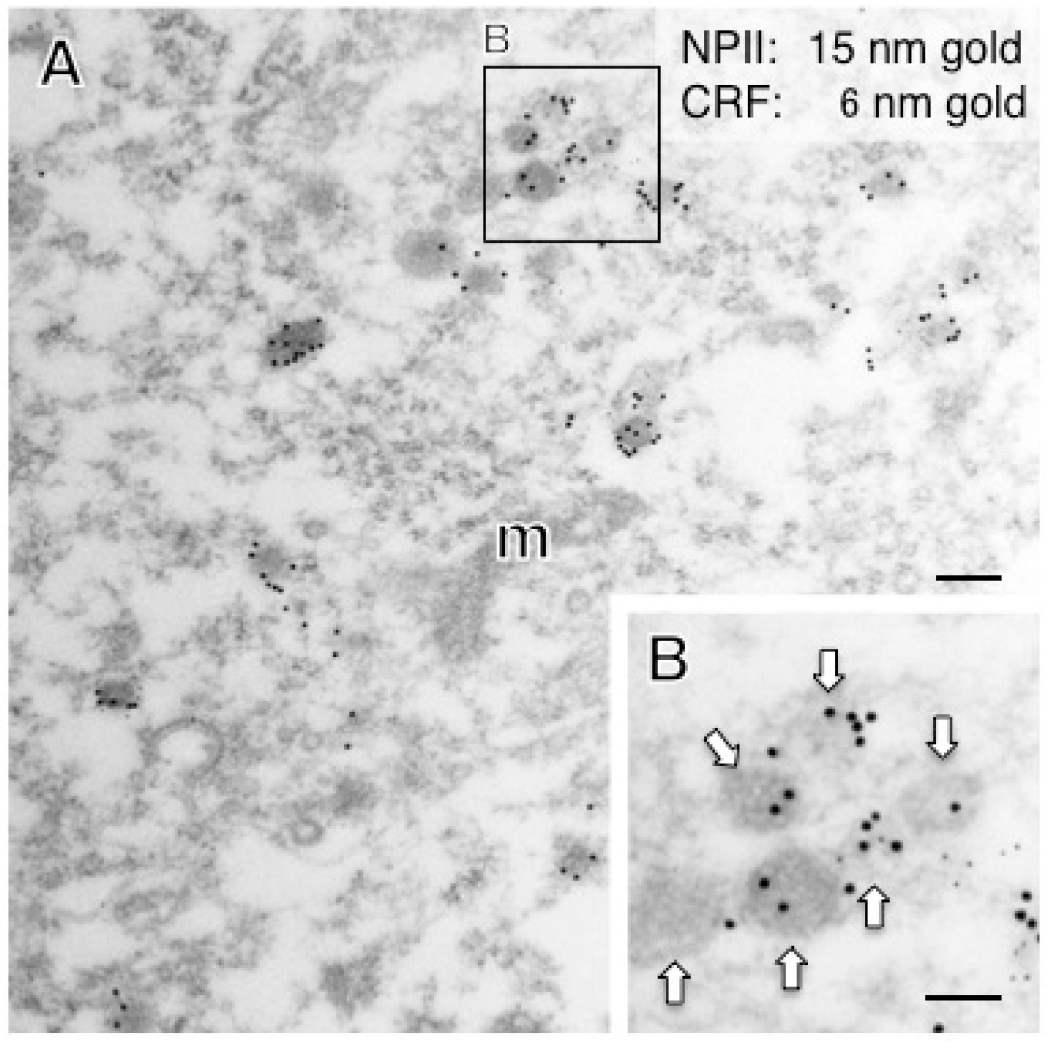

Figure 11. Double-label immunoelectron microscopy for vasopressin-associated neurophysin (NPII) and corticotropin-releasing factor (CRF) in the paraventricular nucleus (PVN) of the hypothalamus in a macaque monkey. (A) In the cell body of a possible parvocellular vasopressin neuron, many dense-cored neurosecretory vesicles located in the cell body were doubly immunopositive for CRF (6-nm gold particles) and NPII (15-nm gold particles). The outlined area in (A) is enlarged in (B). Scale bars, $200 \mathrm{~nm}$, and $100 \mathrm{~nm}$ in the enlarged image. Arrows indicate dense-cored neurosecretory vesicles. $\mathrm{m}$, mitochondrion.

\subsection{Both Magno- and Parvocellular AVP Neurons Are Glutamatergic}

We performed immunoelectron microscopy for L-glutamate in the posterior pituitary in order to determine its occurrence in the terminal regions of magnocellular AVP neurons. The immunoreactivity for glutamate was associated primarily with the clusters of small electron-lucent vesicles in the axonal endings of AVP neurons of posterior pituitary (Figure 12A,B). In contrast, NPII-immunoreactivity was associated with dcv (Figure 12A,B). Next, we examined the terminal regions of parvocellular axons in the median eminence. Triple staining for CRF/NPII/glutamate (Figure 12C,D) showed that, as in the posterior pituitary, glutamate-immunoreactivity was associated with the clusters of electronlucent microvesicles in the parvocellular endings which contained AVP/CRF-positive dcv (Figure 12C,D) and in other similar endings of the terminals of other parvocellular neurosecretory neurons. Due to the mild formaldehyde fixation, the membrane of single microvesicles could not be clearly distinguished. However, a comparison with glutaraldehyde-fixed material leaves no doubt that these are clusters of microvesicles. Similar results were obtained by immunoelectron microscopy for VGLUT2 in both the posterior pituitary and the external layer of the median eminence (Figure 13). Very few gold particles were associated with other intra-varicosity organelles, such as the mitochondria, and background labelling over glial and endothelial elements was also extremely low. Immunoelectron microscopy studies were repeated independently at least three times using different monkeys and always produced similar results. 

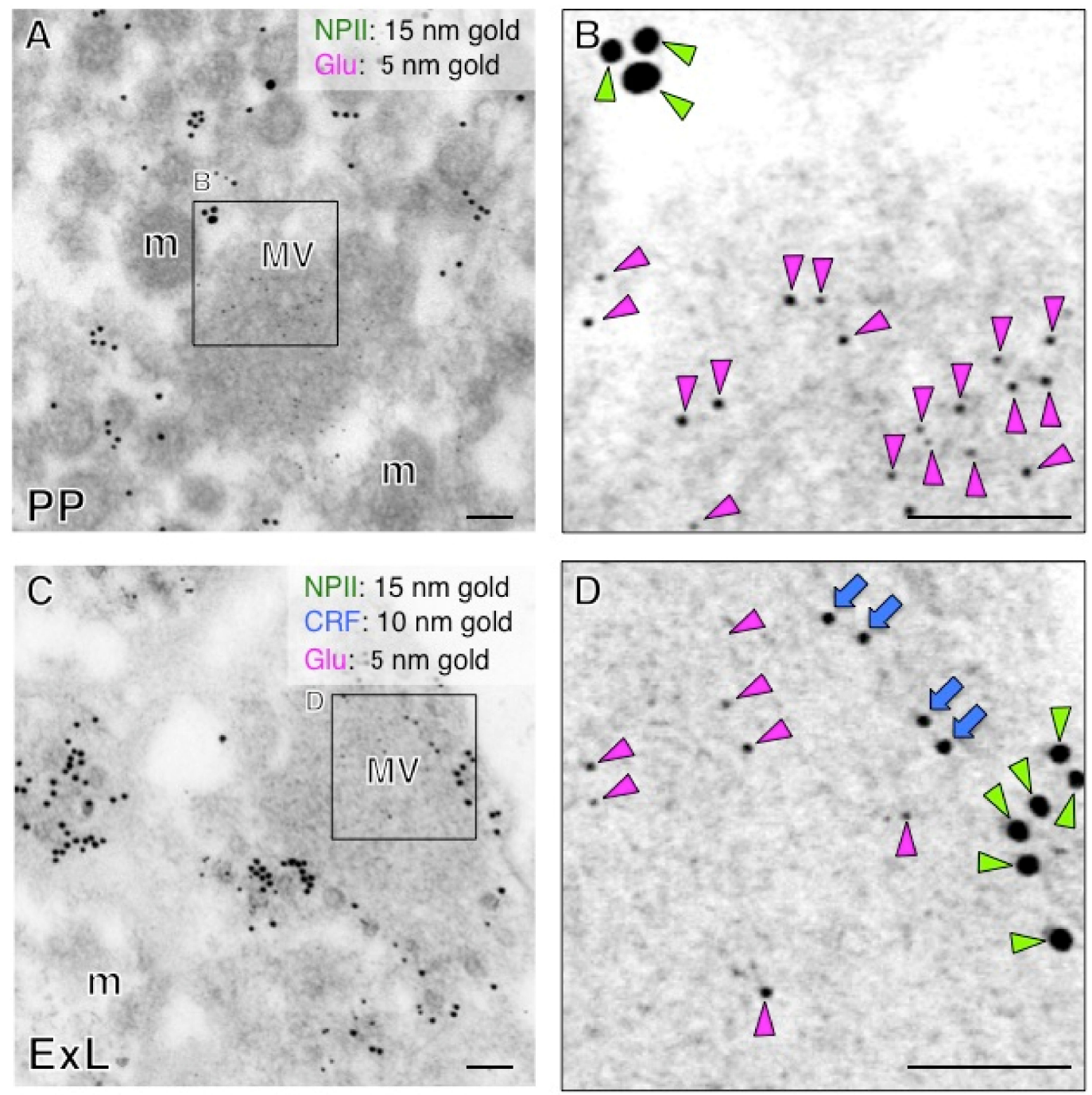

Figure 12. Immunoelectron microscopy for glutamate (Glu) in the posterior pituitary (PP) (A) and external layer of the median eminence (ExL) (C) in a macaque monkey. (B) Double-label immunoelectron microscopy for vasopressin-associated neurophysin (NPII) and Glu shows that Glu-immunoreactivity is associated with microvesicles in the macaque posterior pituitary. (D) Triple-label immunoelectron microscopy for NPII/corticotrophin-releasing factor (CRF)/Glu indicates that Glu-immunoreactivity is associated with electron-lucent small vesicles in the axonal endings, in the NPII/CRF-double positive endings. The outlined areas are enlarged. Scale bars, $100 \mathrm{~nm}$. Green arrowheads indicate NPII-immunoreactivity; blue arrows indicate CRF-immunoreactivity; magenta arrowheads indicate Glu-immunoreactivity. m, mitochondrion; MV, clustered microvesicles. 

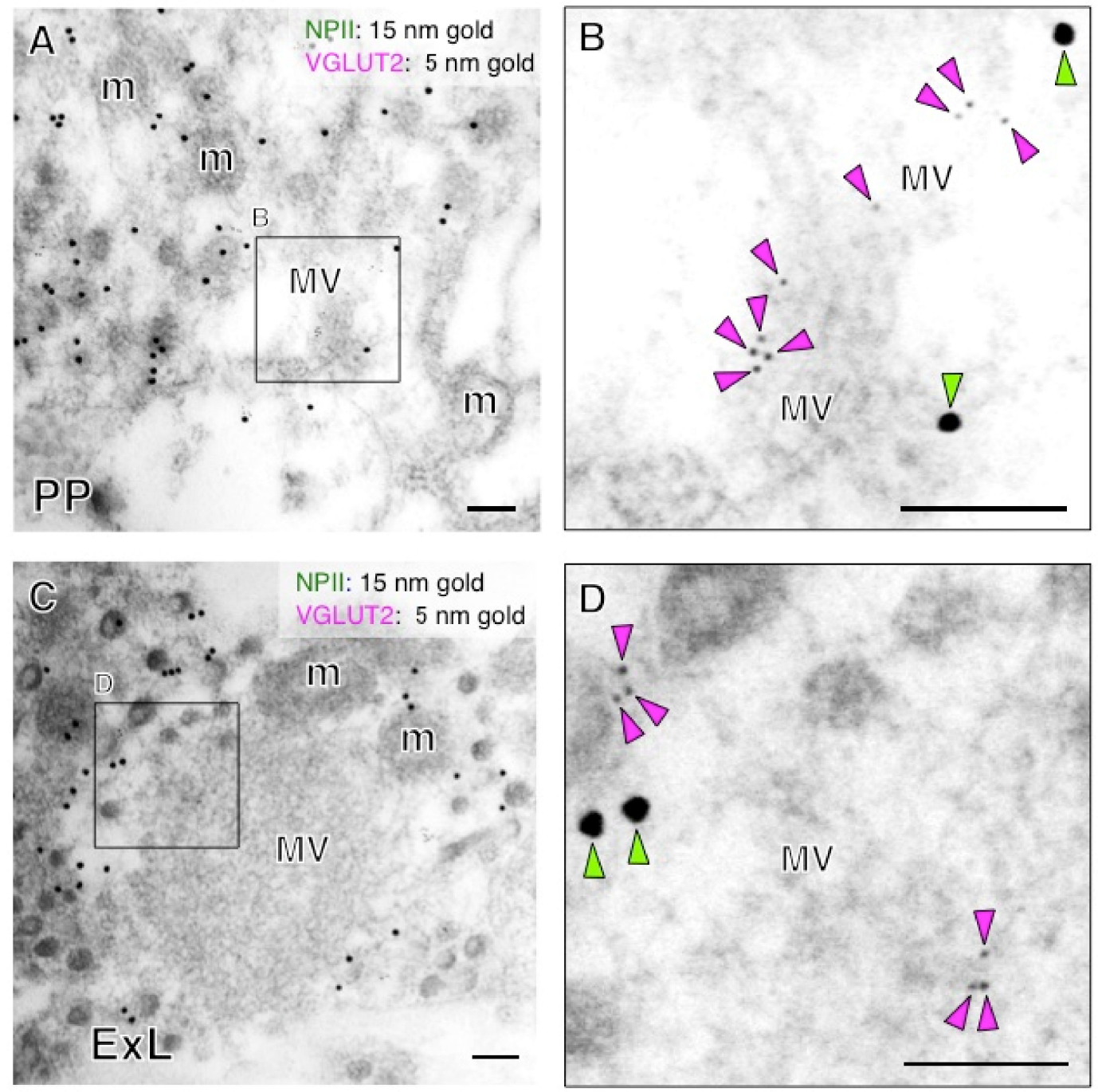

Figure 13. Immunoelectron microscopy for vesicular glutamate transporter 2 (VGLUT2) in the posterior pituitary (PP) (A) and external layer of the median eminence $(\operatorname{ExL})(\mathbf{C})$ in a macaque monkey. (B) Double-label immunoelectron microscopy for vasopressin-associated neurophysin (NPII) and VGLUT2 shows that VGLUT2-immunoreactivity is associated with clustered microvesicles (MV) in the posterior pituitary. (D) Double-label immunoelectron microscopy for NPII/VGLUT2 indicates that VGLUT2-immunoreactivity is associated with the membrane of electron-lucent small vesicles in the vasopressin endings. The outlined areas are enlarged. Scale bars, $100 \mathrm{~nm}$. Green arrowheads indicate NPII-immunoreactivity; magenta arrowheads indicate VGLUT2-immunoreactivity. m, mitochondrion; MV, clustered microvesicles.

\section{Discussion}

It is often assumed that glutaraldehyde, a cross-linking fixative, is essential for the preservation of fine ultrastructure $[19,20]$ and that formaldehyde-only fixed tissues are therefore inappropriate for electron microscopic analyses. However, the use of glutaraldehyde often results in a reduction of immunoreactivity and, for this reason, formaldehydefixed tissues without glutaraldehyde are used in most cases for immunohistochemical analysis at the light microscopic level $[19,20]$. The current study demonstrates that, in the macaque brain, interpretable ultrastructure and adequate ultrastructural immunoreactivity are both preserved in brain tissue even after long-term storage at $-25^{\circ} \mathrm{C}$ for conventional light microscopy, provided that the fixed tissues are post-fixed with $0.1 \%$ glutaraldehyde after the long-term storage. Thus, formalin-fixed macaque brains stored for a long period, at least up to six-years in this study, can be used for immunoelectron microscopic analysis, suggesting that not only macaque brain, but also postmortem formalin-fixed human brain tissue could be amenable to immunoelectron microscopic analysis. It is also possible that it 
could be preserved over decades in antifreeze solution. Furthermore, the ultrastructure of tissues from rare animals such as endangered species might be studied in this way even if they had been prepared for light microscopic immunohistochemistry and stored at $-25^{\circ} \mathrm{C}$ in antifreeze solution.

The methodology used in this study has some obvious advantages in the ultrastructural analysis of the nervous system, in which tissue specimens are necessarily small, particularly where the brain is large, as in macaque monkeys and humans. After confirmation of the specificity of antibodies at the light microscopic level, post-embedding immunoelectron microscopic analysis can readily be performed on adjacent sections. Furthermore, because identification of brain nuclei and/or cells is easier at the light microscopic level, they can then be precisely targeted for post-embedding immunoelectron microscopy.

The size of dcv contained in the terminals of AVP neurons was quantified and compared among the posterior pituitary and internal/external layers of the median eminence. This showed, also for the macaque, the expected significant difference in size of the dcv (Figure 14). It is known that the posterior pituitary and the internal layer of the median eminence contain the axons of magnocellular AVP neurons of the PVN and SON, whereas the external layer of the median eminence is the terminal region of parvocellular AVP neurons of the PVN $[3,8,15]$ and other parvocellular neurons influence the anterior pituitary. In the $\mathrm{dcv}$ of the internal layer of the median eminence through which the magnocellular axons pass en route to the posterior pituitary, the AVP precursor should be processed sufficiently to reveal both prominent NPII- and copeptin-immunoreactivity in almost all of the axons $[14,15,33]$. In the macaque hypothalamus, quantifying only the size of the $\mathrm{dcv}$ in the cell body or its axon allows us to determine the magnocellular or parvocellular identity of the cell. Finally, our study confirms at the electron microscopic level that certain axonal endings in the external layer of the median eminence of macaques are derived from parvocellular AVP neurons of the PVN.

It has been reported that rodent AVP neurons use glutamate as a neurotransmitter $[16,17,35,36]$. In this study, we examined the detectability, and therefore the expression of glutamate and VGLUT2 in the macaque posterior pituitary. We first demonstrated by Western blotting that VGLUT2 was expressed in the macaque posterior pituitary, suggesting that magnocellular AVP (and also oxytocin) neurons use glutamate as a neurotransmitter in Japanese macaque monkeys. Immunoelectron microscopic analysis revealed that the AVP/CRF-immunoreactivity was restricted to the dcv, but the VGLUT2-immunoreactivity was associated with the smaller, electron-lucent microvesicles (Figure 14). Similarly, immunoreactivity for glutamate itself was essentially restricted to regions containing clusters of microvesicles in the axonal endings of AVP neurons in both the posterior pituitary and external layer of the median eminence (Figure 14). Because the antibody for glutamate, an amino acid, is raised against the cross-linking site of glutaraldehyde as the antigen, it is thought to be essential that glutaraldehyde is included in the fixative prior to glutamate immunocytochemistry $[16,17,31]$. In our study, although glutaraldehyde was not included in the primary perfusion fixative, post-fixation of the formaldehyde-fixed tissue with glutaraldehyde enabled us to detect glutamate by immunoelectron microscopy even after prolonged storage. Therefore, the subcellular localization of amino acids appears, surprisingly, to be preserved for a long period even after conventional formaldehyde fixation. These results suggest that the immunoelectron microscopic detection of amino acids including glutamate and GABA would also be possible in conventional formaldehyde-fixed and stored human brain tissue.

Our results in macaque tissue show that glutamate as an excitatory neurotransmitter is in microvesicles both in magno- and parvocellular AVP neurons. Although the localization of glutamate receptors has been reported in the neural lobe, median eminence and anterior pituitary, a clear role for glutamate secretion at these sites remains unknown $[37,38]$. Salt loading has been shown to produce robust increases in the VGLUT2 mRNA of AVP neuron perikarya and in VGLUT2-immunoreactivity in the rat posterior pituitary [39], suggesting that an osmotic challenge could produce an increase in glutamate release in the primate 
magnocellular AVP system (Figure 14). Similarly, a role in the anterior pituitary of glutamate released from parvocellular AVP/CRF neurons into the hypothalamo-hypophysial portal veins remains unclear. Functional implications for glutamate release at the terminals of both magno- and parvocellular AVP neurons remain to be explored.

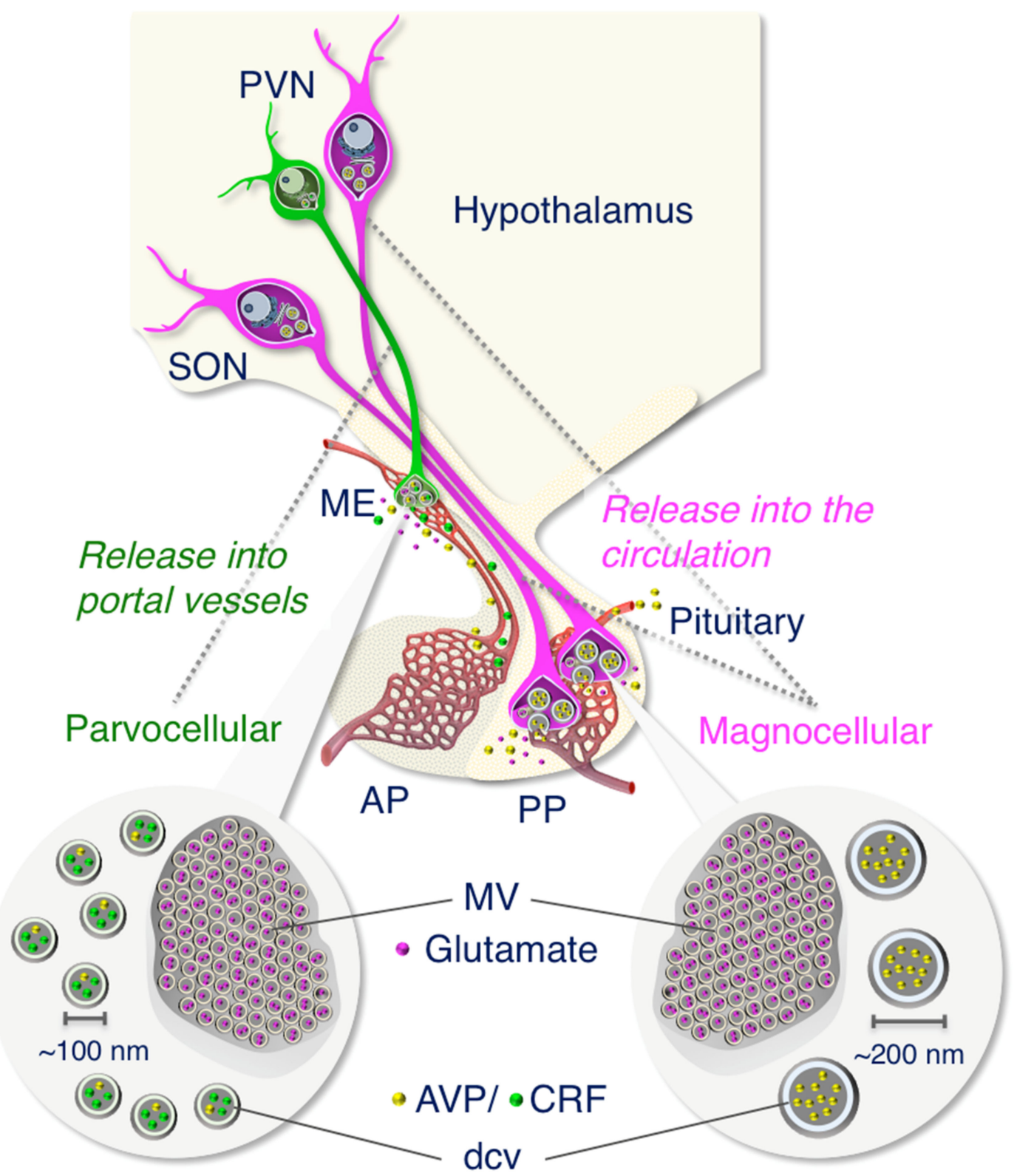

Figure 14. Working model showing that the size difference in dense-cored neurosecretory vesicles (dcv) between magnocellular ( 200 nm) and parvocellular ( 100 nm) vasopressin (AVP)- and/or corticotrophin-releasing factor (CRF)-producing neurons in the hypothalamus of the Japanese macaque monkey. We also demonstrate that both magno- and parvocellular $\mathrm{AVP} / \mathrm{CRF}$ neurons are glutamatergic in primates. AP, anterior pituitary; ME, median eminence; MV, clustered microvesicles; $\mathrm{PP}$, posterior pituitary; PVN, paraventricular nucleus; SON, supraoptic nucleus.

\section{Materials and Methods}

\subsection{Animals}

Three male (2-9-year-old, weight $2.3-12.6 \mathrm{~kg}$ ) and four female (9-11-year-old, weight 7.2-10.8 kg) Japanese macaque monkeys (Macaca fuscata) were used in this study. Macaques were maintained in a temperature-controlled $\left(22-24^{\circ} \mathrm{C}\right)$ room under a daily photoperiod of 12:12 h light/dark cycle (lights off at 8:00 p.m.). These animals were checked and shown to 
be free of specific pathogens. Food and water were available ad libitum. All animals were kept in individual cages. The housing and experimental protocols followed the guidelines of the Ministry of Education, Culture, Sports, Science, and Technology (MEXT) of Japan, and were in accordance with the Guide for the Care and Use of Laboratory Animals prepared by Okayama University (Okayama, Japan), by Tokyo Medical and Dental University (Tokyo, Japan), and by National Institute for Physiological Sciences (Okazaki, Japan). All efforts were made to minimize animal suffering and reduce the number of animals used in this study.

\subsection{Tissue Processing}

Hypothalamic sections and posterior pituitaries were obtained from four macaque monkeys (2 females and 2 males) as described previously [14]. Briefly, macaques were deeply anaesthetized with an overdose of sodium pentobarbital ( $100 \mathrm{mg} / \mathrm{kg}$ body weight), and transcardially perfused with physiological saline followed by $4 \%$ paraformaldehyde (PFA) in $0.1 \mathrm{M}$ phosphate buffer (PB, pH 7.4). After perfusion, brains and pituitaries were immediately removed and immersed in the same fixative for $\sim 16 \mathrm{~h}$ at $4{ }^{\circ} \mathrm{C}$. Coronal $30-\mu \mathrm{m}$ thick sections of the hypothalamus were prepared with a Linear-Slicer (PRO10, Dosaka EM, Kyoto, Japan). Preparations were rinsed with $\mathrm{PB}$ and then immersed in antifreeze solution ( $30 \%$ glycerol, $30 \%$ ethylene glycol, $0.36 \% \mathrm{NaCl}$, and $0.05 \% \mathrm{NaN}_{3}$ in $40 \mathrm{mM} \mathrm{PB}$ ) for storage at $-25{ }^{\circ} \mathrm{C}$ until use. All the initial fixation was done $4-6$ years before the present set of experiments. For Western blot analysis, three female macaques were sacrificed by blood loss under deep pentobarbital anesthesia (see above). Posterior pituitaries were quickly removed, frozen immediately in powdered dry ice, and stored at $-80^{\circ} \mathrm{C}$ until use.

\subsection{Immunofluorescence}

The long-term stored, formaldehyde-fixed sections were rinsed with phosphatebuffered saline (PBS) containing 0.3\% Triton X-100 (Sigma-Aldrich, St. Louis, MO, USA) (PBST) five times for 10 min each. After blocking nonspecific binding with $1 \%$ normal goat serum and 1\% BSA in PBST for 30 min at room temperature, the sections were incubated with mouse monoclonal anti-AVP-NPII antibody (PS41; 1:1000 dilution) and with rabbit antiserum directed against copeptin (1: 10,000 dilution) or with rabbit antiserum directed against CRF (1: 20,000 dilution) for $4-5$ days at $4{ }^{\circ} \mathrm{C}$. The mouse monoclonal NPII antibody has previously shown to be specific for AVP neurons in rodents [26,27] and macaque monkeys [14]. The copeptin $7-14$ (ATQLDGPA) fragment, used as an antigen to produce our copeptin antiserum, is well conserved in mammals. It is identical in rats [40], mice [41], macaque monkeys [14], and humans [40]. The copeptin antiserum has also been characterized previously by our immunohistochemistry [22], Western [23] and dot blot [22] analyses. The rabbit polyclonal antiserum against rat/human CRF (PBL rC70), which was kindly donated by Wylie Vale, has been characterized previously $[14,22,24]$. It was directed against the rat form of CRF, which is identical to the human form, and has also been characterized in non-human primates [14,25]. Alexa Fluor 546-linked goat anti-mouse IgG (Molecular Probes, Eugene, OR, USA) and Alexa Fluor 488-linked goat anti-rabbit IgG (Molecular Probes) were used for detection at 1:1000 dilution. Immunofluorescence studies were repeated independently at least three times using different macaques and always produced similar results. Immunostained sections were viewed by confocal laser scanning microscopy (FluoView 1000, Olympus, Tokyo, Japan). The information for antibodies used in this study is shown in Table 1.

\subsection{Post-Embedding Immunoelectron Microscopy}

The long-term stored, formaldehyde-fixed sections were rinsed with PBS five times for $10 \mathrm{~min}$ each, and re-fixed in 4\% PFA $+0.1 \%$ glutaraldehyde in $0.1 \mathrm{M}$ PB for $4-6 \mathrm{~h}$ at $4{ }^{\circ} \mathrm{C}$. Sections were then rinsed with $0.1 \mathrm{M}$ PB three times for 5 min each, and were dehydrated through increasing concentrations of methanol, flat-embedded in LR Gold resin (Electron Microscopy Sciences, Hatfield, PA, USA) by gently pressing against the 
bottom of the flat-bottom-capsule with a pre-prepared resin block, and polymerized under UV lamps at $-25{ }^{\circ} \mathrm{C}$ for $24 \mathrm{~h}$. Ultrathin sections (70 nm in thickness) were collected on nickel grids coated with (or without for triple labeling) a collodion film, rinsed with PBS several times, then incubated with $2 \%$ normal goat serum and $2 \%$ BSA in $50 \mathrm{mM}$ Tris(hydroxymethyl)-aminomethane-buffered saline (TBS; $\mathrm{pH}$ 8.2) for $20 \mathrm{~min}$ to block non-specific binding. The sections were then incubated with the mouse monoclonal antibody against NPII (1:200 dilution), with the rabbit polyclonal antisera against CRF (1:5000 dilution), copeptin (1:100 dilution), L-glutamate (1:10 dilution, Abcam, Cambridge, UK), and/or with the guinea pig polyclonal antibody against VGLUT2 (1:20 dilution, Synaptic Systems, Göttingen, Germany) for $1 \mathrm{~h}$ at room temperature. After incubation with the primary antibodies, the sections were washed with PBS, then incubated with a goat antibody against rabbit IgG conjugated to 5 or $10 \mathrm{~nm}$ gold particles (1:50 dilution, BBI Solutions, Cardiff, UK) and a goat antibody against mouse IgG conjugated to $15 \mathrm{~nm}$ gold particles (1:50 dilution, BBI Solutions) and/or a goat antibody against guinea pig IgG conjugated to $5 \mathrm{~nm}$ gold particles (1:50 dilution, Nanoprobes, Yaphank, NY, USA) for $1 \mathrm{~h}$ at room temperature. The Abcam antibody to glutamate was raised in rabbit against L-glutamate conjugated to glutaraldehyde as the immunogen. The manufacturer's information shows no measurable cross-reactivity detected against glutamate in peptides or proteins but modest cross-reactivity against D-glutamate. The specificity of this antibody was confirmed by immunostaining in the rat retina [31]. To intensify the detectability of the immunoreaction for CRF in the cell body, a streptavidin-biotin intensification kit (Nichirei, Tokyo, Japan) was used. Tissues were first incubated with the biotinylated goat anti-rabbit IgG antibody for $10 \mathrm{~min}$ at room temperature, followed by incubation in avidinbiotin-horseradish peroxidase (HRP) complex solution for $5 \mathrm{~min}$ at room temperature. The sections were then washed with PBS, incubated with the goat antibody against HRP conjugated to $6 \mathrm{~nm}$ gold particles (1:50 dilution, Jackson ImmunoResearch Laboratory, West Grove, PA, USA) for $1 \mathrm{~h}$ at room temperature.

Triple immunoelectron microscopy with antibodies against CRF, NPII, and glutamate was performed by using the front and back of ultrathin sections mounted on nickel grids without a supporting film. First, immunocytochemistry with a pair of primary antibodies (CRF and NPII) was performed on one side of the section and detected using $15 \mathrm{~nm}$ (mouse) and $10 \mathrm{~nm}$ (rabbit) colloidal gold particles (BBI Solutions), respectively. Next, immunocytochemistry with the other primary rabbit antibody (against glutamate) was performed on the other side of the section and detected by use of $5 \mathrm{~nm}$ colloidal gold particles (BBI Solutions). Immunoelectron microscopy studies were repeated independently at least three times using different macaques and always produced similar results.

Finally, the sections were contrasted with uranyl acetate and lead citrate and viewed using an H-7650 (Hitachi, Tokyo, Japan) or JEM-1010 (JEOL, Tokyo, Japan) electron microscope operated at $80 \mathrm{kV}$. The information for antibodies used in this study is shown in Table 1.

\subsection{Western Blotting}

The lysates derived from posterior pituitaries were boiled in $10 \mu \mathrm{L}$ sample buffer containing $62.5 \mathrm{mM}$ trishydroxymethyl-aminomethane- $\mathrm{HCl}$ (Tris- $\mathrm{HCl} ; \mathrm{pH} .6 .8$ ), 2\% SDS, $25 \%$ glycerol, 10\% 2-mercaptoethanol, and a small amount of bromophenol blue. These samples were run on a 4-20\% SDS-PAGE and electroblotted onto a polyvinylidene difluoride (PVDF) membrane (Bio-Rad Laboratories, Hercules, CA, USA) from the gel by a semidry blotting apparatus (Bio-Rad Laboratories). The blotted membranes were blocked with PVDF Blocking Reagent for Can Get Signal (TOYOBO, Tokyo, Japan) for $30 \mathrm{~min}$ at room temperature and incubated overnight at $4{ }^{\circ} \mathrm{C}$ with anti-AVP-NPII mouse monoclonal antibody (PS41; 1:1000 dilution) or anti-VGLUT2 guinea pig polyclonal antibody (1:10,000 dilution) in Can Get Signal Solution 1 (TOYOBO). The blotted membranes were rinsed three times with $0.05 \%$ Tween 20 in Tris-HCl-buffered saline (TBST) and incubated with horseradish peroxidase-conjugated goat polyclonal antibody against mouse IgG (Bio-Rad 
Laboratories) or guinea pig IgG (Bioss Inc., Woburn, MA, USA) 1:10,000 dilution in Can Get Signal Solution 2 (TOYOBO) for $1 \mathrm{~h}$ at room temperature. After washing for three times with TBST, blots were visualized by Immun-Star WesternC Chemiluminescence Kit (Bio-Rad Laboratories). The information for antibodies used in this study is shown in Table 1 . Western blotting analyses were repeated independently at least three times using different macaques and always produced similar results.

\subsection{Statistical Analysis}

All data values were expressed as mean \pm standard error of the mean (SEM) and were analyzed using Statcel4 software. Statistical significance was determined as $p<0.05$ using one-way analysis of variance (ANOVA). When significant difference was found by ANOVA, the post hoc Tukey-Kramer test was performed. All the various analyses in this study were conducted "blind". All electron micrographs were coded and evaluated without the knowledge of the tissue, and the code was not broken until the analysis was complete.

\section{Conclusions}

We report the immunoelectron microscopic characterization of AVP-producing neurons in primate hypothalamo-pituitary systems by the use of formaldehyde-fixed tissues stored at $-25^{\circ} \mathrm{C}$ for up to six years in this study. The size difference in dcv between magno- and parvocellular AVP neurons in Japanese macaque monkeys was determined (Figure 14). Furthermore, we have determined that, despite the prolonged fixation and storage, the size of the magnoand parvocellular dcv was virtually identical to that observed in freshly fixed and embedded tissue $[8,23,42-45]$. We also demonstrate by immunoelectron microscopy that both magno- and parvocellular AVP neurons are glutamatergic in primates (Figure 14). These results show, for the macaque brain, that interpretable neuronal ultrastructure and sufficient immunoreactivity for several relevant proteins are preserved even after a long-term storage of tissues fixed in formaldehyde for light microscopy. They indicate that this methodology could be applied to human post-mortem brain and, therefore, be very useful in translational research.

Author Contributions: Conceptualization, H.S.; methodology, A.O., S.M., T.O., K.S., Y.U. and H.S.; validation, A.O. and H.S.; data curation, A.O. and H.S.; formal analysis, A.O. and H.S.; investigation, A.O., S.M., T.O., K.S. and H.S.; resources, T.O., K.S., Y.U. and H.S.; software, A.O.; visualization, A.O. and H.S.; writing—original draft preparation, H.S.; writing—review and editing, J.F.M.; interpreted the data and provided advice and equipment, Y.U., J.F.M. and T.S.; supervision and project administration, H.S.; funding acquisition, T.O., T.S. and H.S. All authors have read and agreed to the published version of the manuscript.

Funding: This work was supported by Grants-in-Aid for Scientific Research from the Japan Society for the Promotion of Science (JSPS) KAKENHI [to H.S.; 15K15202, 15H05724, 15KK025708, 16H06280 (Advanced Bioimaging Support; ABiS); to T.S.; 21H02520; to T.O.; 20K15837], by Grant-in-Aid for Scientific Research on Innovative Areas "Singularity Biology (No.8007)" of MEXT, Japan (to T.S.; 21H00428), and by the Research Grant from the Suzuken Memorial Foundation, Japan (to H.S.; 19-085). T.O. and K.S. were supported by Research Fellowships of JSPS for Young Scientists.

Institutional Review Board Statement: This study was conducted according to the guidelines of the Declaration of Helsinki, and approved by the Institutional Ethics Committees of Okayama UniversityNational Institute for Physiological Sciences joint research (Protocol Code MOFF-np-2014-008 and date of approval: 20 April 2015) and Tokyo Medical and Dental University (protocol code A2018-241C and date of approval: 18 October 2018).

Informed Consent Statement: Not applicable.

Data Availability Statement: All data generated or analyzed during this study are included in the manuscript. All relevant data of this manuscript are available from the corresponding author upon reasonable request.

Acknowledgments: Tissues of Nihonzaru (Japanese macaque monkeys) were provided by National Institutes of Natural Sciences (NINS) and Kyoto University Primate Research Institute (KUPRI) with 
support in part by the National Bio-Resource Project (NBRP) of the Ministry of Education, Culture, Sports, Science and Technology (MEXT), Japan. We thank Narumi Katsuyama (Tokyo Medical and Dental University, Japan), Kei Tamaura and Ray Nomura for their technical support. We are grateful to Wylie Vale for the supply of an antiserum against CRF.

Conflicts of Interest: The authors declare no conflict of interest.

$\begin{array}{ll}\text { Abbreviations } \\ \text { ANOVA } & \text { analysis of variance } \\ \text { AVP } & \text { arginine vasopressin } \\ \text { CRF } & \text { corticotrophin-releasing factor } \\ \text { dcv } & \text { dense-cored neurosecretory vesicle } \\ \text { HRP } & \text { horseradish peroxidase } \\ \text { NP } & \text { neurophysin } \\ \text { PB } & \text { phosphate buffer } \\ \text { PBS } & \text { phosphate-buffered saline } \\ \text { PFA } & \text { paraformaldehyde } \\ \text { PVDF } & \text { polyvinylidene difluoride } \\ \text { PVN } & \text { paraventricular nucleus } \\ \text { SEM } & \text { standard error of the mean } \\ \text { SON } & \text { supraoptic nucleus } \\ \text { Tris-HCl } & \text { trishydroxymethyl-aminomethane- HCl } \\ \text { TBST } & \text { Tris-HCl-buffered saline } \\ \text { VGLUT2 } & \text { vesicular glutamate transporter 2 }\end{array}$

\section{References}

1. Abbott, A. Biomedicine: The changing face of primate research. Nature 2014, 506, 24-26. [CrossRef] [PubMed]

2. Walum, H.; Young, L.J. The neural mechanisms and circuitry of the pair bond. Nat. Rev. Neurosci. 2018, 19, 643-654. [CrossRef] [PubMed]

3. Buijs, R.M.; De Vries, G.J.; Van Leeuwen, F.W.; Swaab, D.F. Vasopressin and oxytocin: Distribution and putative functions in the brain. Prog. Brain Res. 1983, 60, 115-122. [CrossRef] [PubMed]

4. Breslow, E. Structure and folding properties of neurophysin and its peptide complexes: Biological implications. Regul. Pept. 1993, 45, 15-19. [CrossRef]

5. Davies, J.; Waller, S.; Zeng, Q.; Wells, S.; Murphy, D. Further delineation of the sequences required for the expression and physiological regulation of the vasopressin gene in transgenic rat hypothalamic magnocellular neurones. J. Neuroendocrinol. 2003, 15, 42-50. [CrossRef]

6. Land, H.; Schutz, G.; Schmale, H.; Richter, D. Nucleotide sequence of cloned cDNA encoding bovine arginine vasopressinneurophysin II precursor. Nature 1982, 295, 299-303. [CrossRef]

7. Koshimizu, T.A.; Nakamura, K.; Egashira, N.; Hiroyama, M.; Nonoguchi, H.; Tanoue, A. Vasopressin V1a and V1b receptors: From molecules to physiological systems. Physiol. Rev. 2012, 92, 1813-1864. [CrossRef]

8. Morris, J. Neurosecretory Vesicles: Structure, Distribution, Release and Breakdown. In Neurosecretion: Secretory Mechanisms; Lemons, J.R., Dayanithi, G., Eds.; Springer Nature Switzerland: Cham, Switzerland, 2020; Volume 8, pp. 81-102.

9. Vale, W.; Spiess, J.; Rivier, C.; Rivier, J. Characterization of a 41-residue ovine hypothalamic peptide that stimulates secretion of corticotropin and beta-endorphin. Science 1981, 213, 1394-1397. [CrossRef] [PubMed]

10. Fellmann, D.; Bugnon, C.; Bresson, J.L.; Gouget, A.; Cardot, J.; Clavequin, M.C.; Hadjiyiassemis, M. The CRF neuron: Immunocytochemical study. Peptides 1984, 5 (Suppl. 1), 19-33. [CrossRef]

11. Itoi, K.; Talukder, A.H.; Fuse, T.; Kaneko, T.; Ozawa, R.; Sato, T.; Sugaya, T.; Uchida, K.; Yamazaki, M.; Abe, M.; et al. Visualization of corticotropin-releasing factor neurons by fluorescent proteins in the mouse brain and characterization of labeled neurons in the paraventricular nucleus of the hypothalamus. Endocrinology 2014, 155, 4054-4060. [CrossRef]

12. Mouri, T.; Itoi, K.; Takahashi, K.; Suda, T.; Murakami, O.; Yoshinaga, K.; Andoh, N.; Ohtani, H.; Masuda, T.; Sasano, N. Colocalization of corticotropin-releasing factor and vasopressin in the paraventricular nucleus of the human hypothalamus. Neuroendocrinology 1993, 57, 34-39. [CrossRef]

13. Whitnall, M.H.; Mezey, E.; Gainer, H. Co-localization of corticotropin-releasing factor and vasopressin in median eminence neurosecretory vesicles. Nature 1985, 317, 248-250. [CrossRef]

14. Otubo, A.; Kawakami, N.; Maejima, S.; Ueda, Y.; Morris, J.F.; Sakamoto, T.; Sakamoto, H. Vasopressin gene products are colocalised with corticotrophin-releasing factor within neurosecretory vesicles in the external zone of the median eminence of the Japanese macaque monkey (Macaca fuscata). J. Neuroendocrinol. 2020, 32, e12875. [CrossRef] [PubMed] 
15. Zimmerman, E.A.; Carmel, P.W.; Husain, M.K.; Ferin, M.; Tannenbaum, M.; Frantz, A.G.; Robinson, A.G. Vasopressin and neurophysin: High concentrations in monkey hypophyseal portal blood. Science 1973, 182, 925-927. [CrossRef] [PubMed]

16. Meeker, R.B.; Swanson, D.J.; Greenwood, R.S.; Hayward, J.N. Ultrastructural distribution of glutamate immunoreactivity within neurosecretory endings and pituicytes of the rat neurohypophysis. Brain Res. 1991, 564, 181-193. [CrossRef]

17. Meeker, R.B.; Swanson, D.J.; Hayward, J.N. Light and electron microscopic localization of glutamate immunoreactivity in the supraoptic nucleus of the rat hypothalamus. Neuroscience 1989, 33, 157-167. [CrossRef]

18. Valentino, R.J.; Rudoy, C.; Saunders, A.; Liu, X.B.; Van Bockstaele, E.J. Corticotropin-releasing factor is preferentially colocalized with excitatory rather than inhibitory amino acids in axon terminals in the peri-locus coeruleus region. Neuroscience 2001, 106, 375-384. [CrossRef]

19. Maunsbach, A.B. The influence of different fixatives and fixation methods on the ultrastructure of rat kidney proximal tubule cells. II. Effects of varying osmolality, ionic strength, buffer system and fixative concentration of glutaraldehyde solutions. J. Ultrastruct. Res. 1966, 15, 283-309. [CrossRef]

20. Maunsbach, A.B. The influence of different fixatives and fixation methods on the ultrastructure of rat kidney proximal tubule cells. I. Comparison of different perfusion fixation methods and of glutaraldehyde, formaldehyde and osmium tetroxide fixatives. J. Ultrastruct. Res. 1966, 15, 242-282. [CrossRef]

21. Balaram, P.; Hackett, T.A.; Kaas, J.H. Differential expression of vesicular glutamate transporters 1 and 2 may identify distinct modes of glutamatergic transmission in the macaque visual system. J. Chem. Neuroanat. 2013, 50-51, 21-38. [CrossRef] [PubMed]

22. Kawakami, N.; Otubo, A.; Maejima, S.; Talukder, A.H.; Satoh, K.; Oti, T.; Takanami, K.; Ueda, Y.; Itoi, K.; Morris, J.F.; et al. Variation of pro-vasopressin processing in parvocellular and magnocellular neurons in the paraventricular nucleus of the hypothalamus: Evidence from the vasopressin-related glycopeptide copeptin. J. Comp. Neurol. 2021, 529, 1372-1390. [CrossRef] [PubMed]

23. Satoh, K.; Oti, T.; Katoh, A.; Ueta, Y.; Morris, J.F.; Sakamoto, T.; Sakamoto, H. In vivo processing and release into the circulation of GFP fusion protein in arginine vasopressin enhanced GFP transgenic rats: Response to osmotic stimulation. FEBS J. 2015, 282, 2488-2499. [CrossRef]

24. Sawchenko, P.E.; Swanson, L.W.; Vale, W.W. Co-expression of corticotropin-releasing factor and vasopressin immunoreactivity in parvocellular neurosecretory neurons of the adrenalectomized rat. Proc. Natl. Acad. Sci. USA 1984, 81, 1883-1887. [CrossRef]

25. Foote, S.L.; Cha, C.I. Distribution of corticotropin-releasing-factor-like immunoreactivity in brainstem of two monkey species (Saimiri sciureus and Macaca fascicularis): An immunohistochemical study. J. Comp. Neurol. 1988, 276, 239-264. [CrossRef] [PubMed]

26. Wang, H.; Ward, A.R.; Morris, J.F. Oestradiol acutely stimulates exocytosis of oxytocin and vasopressin from dendrites and somata of hypothalamic magnocellular neurons. Neuroscience 1995, 68, 1179-1188. [CrossRef]

27. Castel, M.; Morris, J.F.; Whitnall, M.H.; Sivan, N. Improved visualization of the immunoreactive hypothalamo-neurohypophysial system by use of immuno-gold techniques. Cell Tissue Res. 1986, 243, 193-204. [CrossRef]

28. Castel, M.; Morris, J.F. The neurophysin-containing innervation of the forebrain of the mouse. Neuroscience 1988, $24,937-966$. [CrossRef]

29. Frahm, S.; Antolin-Fontes, B.; Gorlich, A.; Zander, J.F.; Ahnert-Hilger, G.; Ibanez-Tallon, I. An essential role of acetylcholineglutamate synergy at habenular synapses in nicotine dependence. eLife 2015, 4, e11396. [CrossRef]

30. Mills, F.; Globa, A.K.; Liu, S.; Cowan, C.M.; Mobasser, M.; Phillips, A.G.; Borgland, S.L.; Bamji, S.X. Cadherins mediate cocaine-induced synaptic plasticity and behavioral conditioning. Nat. Neurosci. 2017, 20, 540-549. [CrossRef]

31. Sun, D.; Vingrys, A.J.; Kalloniatis, M. Metabolic and functional profiling of the normal rat retina. J. Comp. Neurol. 2007, 505, 92-113. [CrossRef] [PubMed]

32. Hou, S.; Duale, H.; Cameron, A.A.; Abshire, S.M.; Lyttle, T.S.; Rabchevsky, A.G. Plasticity of lumbosacral propriospinal neurons is associated with the development of autonomic dysreflexia after thoracic spinal cord transection. J. Comp. Neurol. 2008, 509, 382-399. [CrossRef]

33. Kawata, M.; Sano, Y. Immunohistochemical identification of the oxytocin and vasopressin neurons in the hypothalamus of the monkey (Macaca fuscata). Anat. Embryol. 1982, 165, 151-167. [CrossRef]

34. Cannata, M.A.; Morris, J.F. Changes in the appearance of hypothalamo-neurohypophysial neurosecretory granules associated with their maturation. J. Endocrinol. 1973, 57, 531-538. [CrossRef] [PubMed]

35. Ziegler, D.R.; Cullinan, W.E.; Herman, J.P. Distribution of vesicular glutamate transporter mRNA in rat hypothalamus. J. Comp. Neurol. 2002, 448, 217-229. [CrossRef]

36. Zhang, L.; Hernandez, V.S.; Zetter, M.A.; Eiden, L.E. VGLUT-VGAT expression delineates functionally specialised populations of vasopressin-containing neurones including a glutamatergic perforant path-projecting cell group to the hippocampus in rat and mouse brain. J. Neuroendocrinol. 2020, 32, e12831. [CrossRef]

37. Hrabovszky, E.; Liposits, Z. Glutamatergic phenotype of hypothalamic neurosecretory systems: A novel aspect of central neuroendocrine regulation. Ideggyogy Sz. 2007, 60, 182-186. [PubMed]

38. Brann, D.W. Glutamate: A major excitatory transmitter in neuroendocrine regulation. Neuroendocrinology 1995, 61, 213-225. [CrossRef] [PubMed]

39. Hrabovszky, E.; Csapo, A.K.; Kallo, I.; Wilheim, T.; Turi, G.F.; Liposits, Z. Localization and osmotic regulation of vesicular glutamate transporter-2 in magnocellular neurons of the rat hypothalamus. Neurochem. Int. 2006, 48, 753-761. [CrossRef] 
40. Rehbein, M.; Hillers, M.; Mohr, E.; Ivell, R.; Morley, S.; Schmale, H.; Richter, D. The neurohypophyseal hormones vasopressin and oxytocin. Precursor structure, synthesis and regulation. Biol. Chem. Hoppe-Seyler 1986, 367, 695-704. [CrossRef]

41. Hara, Y.; Battey, J.; Gainer, H. Structure of mouse vasopressin and oxytocin genes. Brain Res. Mol. Brain Res. 1990, 8, 319-324. [CrossRef]

42. Naugle, M.M.; Lozano, S.A.; Guarraci, F.A.; Lindsey, L.F.; Kim, J.E.; Morrison, J.H.; Janssen, W.G.; Yin, W.; Gore, A.C. Age and Long-Term Hormone Treatment Effects on the Ultrastructural Morphology of the Median Eminence of Female Rhesus Macaques. Neuroendocrinology 2016, 103, 650-664. [CrossRef] [PubMed]

43. Holmes, R.L. Comparative Observations on Inclusions in Nerve Fibres of the Mammalian Neurohypophysis. Z Zellforsch Mikrosk Anat. 1964, 64, 474-492. [CrossRef] [PubMed]

44. Armstrong, W.E.; Tian, M. Separate ultrastructural distributions of neurophysin and C-terminal glycopeptide within dense core vesicles in rat neural lobe. Brain Res. 1991, 562, 144-148. [CrossRef]

45. Morris, J.F. Hormone storage in individual neurosecretory granules of the pituitary gland: A quantitative ultrastructural approach to hormone storage in the neural lobe. J. Endocrinol. 1976, 68, 209-224. [CrossRef] [PubMed] 